\title{
5. Acontecimentos recentes e desafios para o futuro
}

\section{2-2014: uma nova indústria começa a decolar - a dos biocombustiveis para a aviação}

O Projeto PITE ${ }^{1}$ /Fapesp Roadmap Biocombustíveis Sustentáveis para a Aviação no Brasil $^{2}$, coordenado por Luís Cortez, da Unicamp, uma parceria da Fapesp com a Boeing e a Embraer e vários stakeholders, visou abrir caminho às pesquisas no Brasil para esse novo mercado, os biocombustiveis aeronáuticos (Figura 118). A partir de duas metas estabelecidas pela indústria da aviação no mundo - ter crescimento sem aumentar as emissões de GEE a partir de 2020 e reduzir as emissões de GEE à metade a partir de 2050 - foi lançado o desafio para as pesquisas. O Brasil, pelas condições excepcionais que possui (abundância de terras, condições naturais e capacitação humana), tem uma grande oportunidade de contribuir para desenvolver essa indústria em escala mundial. As rotas estudadas para a produção de biocombustíveis aeronáuticos no Brasil são apresentadas na Figura 119.

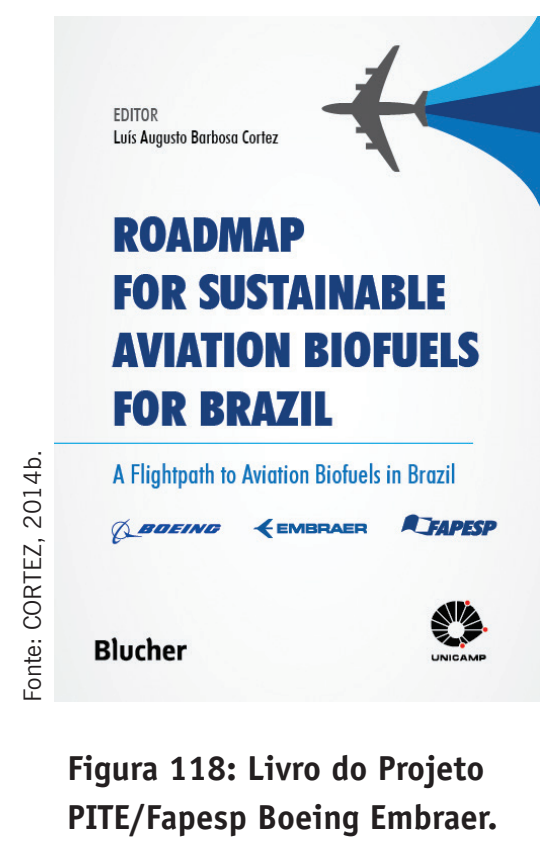

Programa de Apoio à Pesquisa em Parceria para Inovação Tecnológica (PITE).

2 Ver $<$ http://openaccess.blucher.com.br/article-list/roadmap-aviation-272/list\#articles $>$. 
A equipe contou também com Francisco Nigro, Telma Franco, Luiz Augusto Horta Nogueira, Ulf Schuchardt, Heitor Cantarella, André Nassar, Rodrigo Leal, Márcia Azanha Ferraz Dias de Moraes, entre outros pesquisadores.

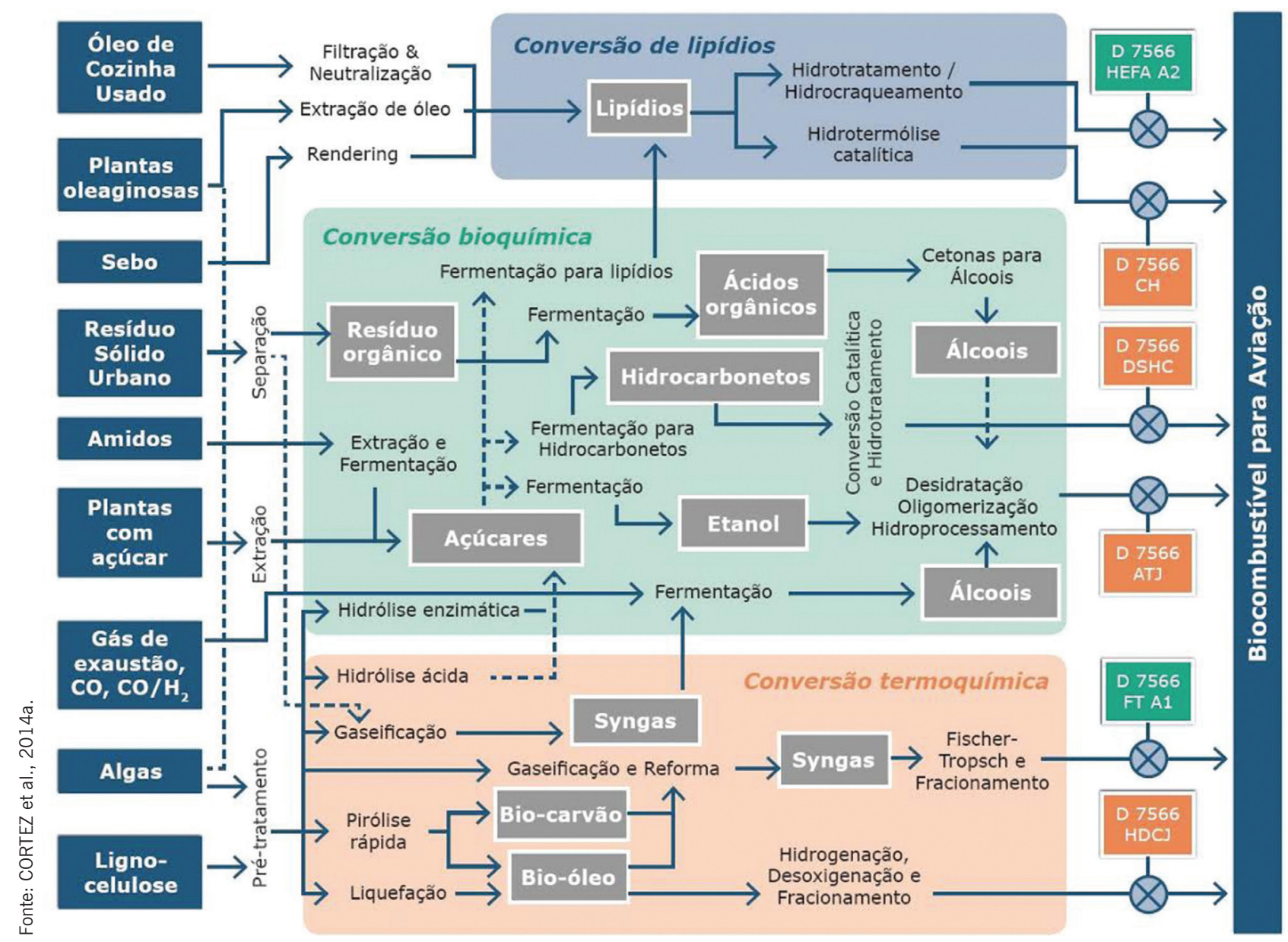

Figura 119: Rotas para a produção de biocombustiveis para a aviação. 


\section{4}

\section{A Dedini S/A Indústrias de Base completa 94 anos $^{3}$}

A Dedini completou 94 anos em 2014, destacando-se como líder mundial no fornecimento de equipamentos e plantas completas para o setor sucroalcooleiro. Um resumo das plantas com tecnologia Dedini até dezembro de 2013 é apresentado na Tabela 8.

Tabela 8: Plantas completas fornecidas para o setor sucroalcooleiro pela Dedini até dezembro de 2013

\begin{tabular}{lc}
\hline \multicolumn{1}{c}{ Tecnologias Dedini } & Unidades \\
\hline Destilarias de bioetanol no Brasil & 875 \\
\hline Usinas completas de bioetanol turn-key no Brasil & 108 \\
\hline Plantas turn-key açúcar/bioetanol no exterior ${ }^{1}$ & 29 \\
\hline Ternos de moenda & 2.633 \\
\hline Caldeiras & 1.256 \\
\hline Plantas de cogeração (turn-key) & 114 \\
\hline
\end{tabular}

Nota 1: Venezuela, Equador, Uruguai, México, Haiti, Paquistão, Etiópia, Guatemala, Argentina, Perú, Costa Rica, Paraguai, Ilhas Virgens, Bolívia, Jamaica, Sudão. Fonte: Olivério, J.L. (2014).

\section{Nagise publica levantamento sobre inovação no etanol}

O Núcleo de Apoio à Gestão da Inovação no Setor Sucro-energético (Nagise), criado em 2012 e conduzido por um conjunto de instituições públicas e privadas, realizou um trabalho de levantamento da situação da inovação dentro de um conjunto de mais de cinquenta grandes empresas do setor no Brasil. Esse levantamento, intitulado Futuro do bioetanol: O Brasil na liderança? e coordenado por Sérgio Salles Filho, do Instituto de Geociência (IG) e da Faculdade de Ciências Aplicadas (FCA) da Unicamp, publicado em 2014, é um diagnóstico que mostra quem inova e como inova. Esse diagnóstico mostra um "copo meio cheio", o que significa que, embora haja um conjunto importante de empresas com esforços sistemáticos de pesquisa e

3 Ver $<$ www.codistil.com.br/index.php?option=com_content\&view=article\&id=25\&Itemid $=45 \&$ lang $=$ pt $>$. 
inovação, há ainda um conjunto não menos importante que apenas começa a introduzir o assunto da P\&D e da inovação em suas estratégias e rotinas. $\mathrm{O}$ setor apresenta um terço de empresas inovadoras, um terço de empresas que começam a investir de forma mais significativa e um terço ainda por iniciar investimentos.

Por qualquer lado que se olhe, o tema da inovação está presente, mas há um caminho de modernização e de mudanças de visão que precisa ser percorrido para que o setor ganhe mais competitividade no longo prazo. O livro Global ethanol: evolution, risks and uncertainties, que trata da inovação no setor sucroalcooleiro e do futuro do etanol combustível, acaba de ser publicado por Salles Filho et al. (2016).

\section{BBEST e a SBE}

Durante o II Brazilian Bioenergy Science and Technology Conference (BBEST), em Campos do Jordão, foi criada a Sociedade de Bioenergia (SBE) (The Bioenergy Society) ${ }^{4}$, presidida por Luís Cortez, com o objetivo de trabalhar em prol da bioenergia sustentável. Outros eventos acadêmicos, como o AGRENER, hoje em sua décima edição ${ }^{5}$ e nascido como Encontro de Energia no Meio Rural, em 1986 em Itajubá, e o CONBEA ${ }^{6}$, Congresso Brasileiro de Engenharia Agrícola (44 eventos realizados), em muito contribuíram para promover as discussões científicas do álcool combustível no Brasil.

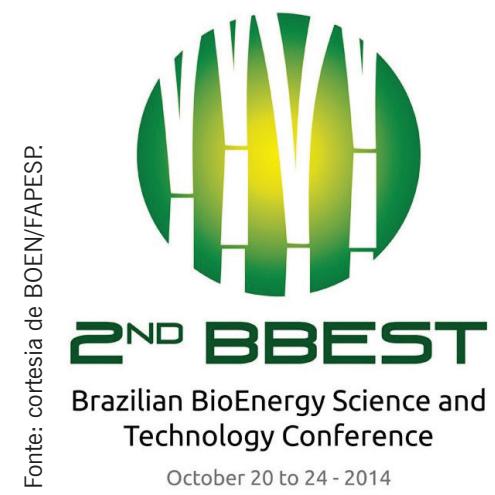

(a)
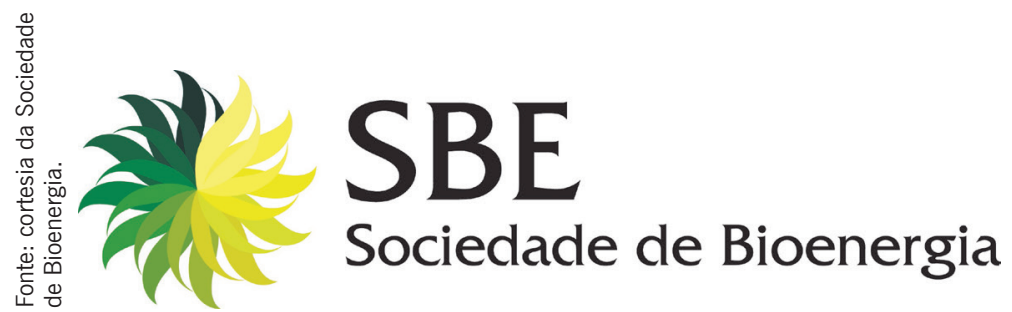

(b)

Figuras 120a e 120b: BBEST e Sociedade de Bionergia.

\footnotetext{
4 Ver $<$ bioenFapesp.org/index.php?option=com_content\&view=article\&id=228\&Itemid=228>.

Ver $<$ www.iee.usp.br/?q=pt-br/evento/x-agrener-gd-2015>.

Ver $<$ http://agroevento.com/agenda/conbea-2015/>.
} 


\section{Lançamento do World directory of advanced renewable fuels and chemicals}

Em 2014, durante o II BBEST, é lançado o livro sobre empresas dedicadas à inovação no setor de bioenergia (Figura 121).

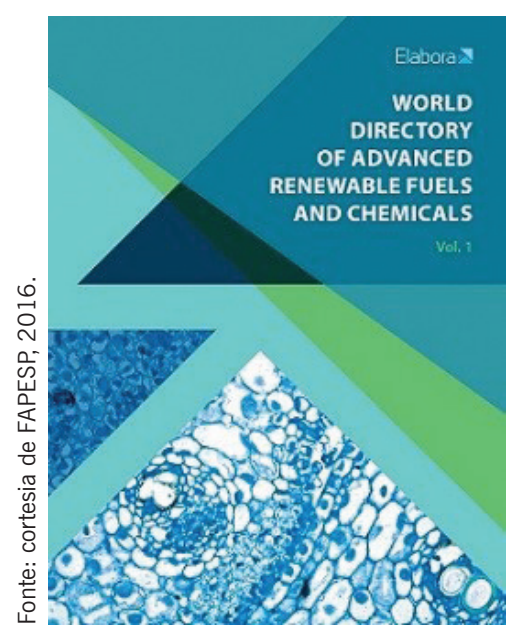

Figura 121: World directory of advanced renewable fuels and chemicals.

O trabalho, coordenado por João Eduardo de Morais Pinto Furtado, envolveu o levantamento de tecnologias e projetos em escala global, que resultou em um volume que traz informações sobre 250 iniciativas de 28 países, envolvendo mais de 600 parceiros, entre empresas, usuários intensivos de energia, fundos de investimento, universidades, institutos de ciência e tecnologia (ICTs) e governos. O diretório apresenta os resultados da pesquisa para compreender o potencial das alternativas de produção de biocombustíveis e de bioquímicos avançados de origem renovável.

Outro mapeamento das contribuições brasileiras no campo da inovação para o setor sucroalcooleiro tem sido feito por pesquisadores do Instituto de Geociências (IG) da Unicamp (André Tosi Furtado e Sérgio Robles Reys de Queiroz).

7 Ver < http://finep.gov.br/noticias/todas-noticias/4163-lancado-o-anuario-world-directory-of-advanced-renewable-fuels-and-chemicals $>$. 


\section{Publicação do livro Production of Ethanol from Sugarcane in Brazil, from State Intervention to a Free Market}

Em 2014 foi também publicado o livro Production of Ethanol from Sugarcane in Brazil, from State Intervention to a Free Market, de autoria de Márcia Azanha Ferraz Dias de Moraes (Figura 122) com David Zilberman, da Universidade da Califórnia, Berkeley, e com apoio Fapesp. O livro apresenta uma evolução da cadeia produtiva da cana-de-açúcar no Brasil, destacando o período de criação do Proálcool, e analisando em profundidade o período de desregulamentação do setor, ou seja, a redução da intervenção do Estado. Os autores analisam também o período recente e as principais mudanças após a saída do Estado, expõe a questão política e os diferentes interesses envolvidos e a sua visão de futuro da bioenergia no país.

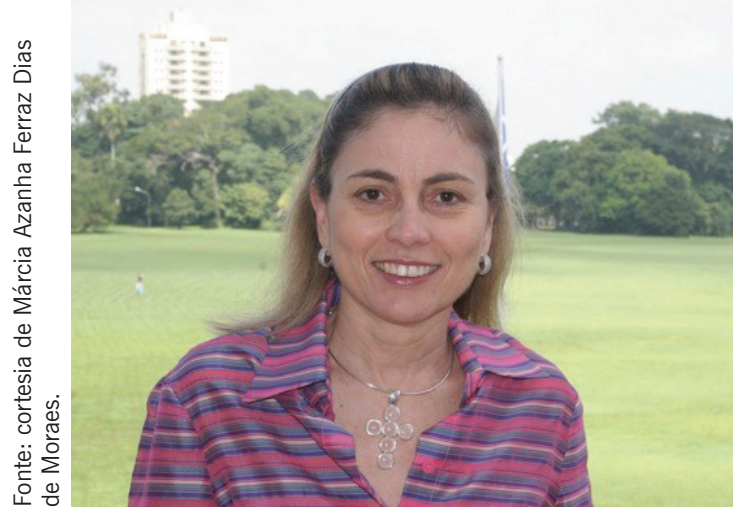

Figura 122: Márcia Azanha Ferraz Dias de Moraes.

\section{5}

\section{Criação do CEPID PSA/PEGEOUT/CITROËN}

Em 2015 foi criado um Centro de Pesquisas e Inovação da Fapesp na Faculdade de Engenharia Mecânica da Unicamp, para realizar P\&D em motores a etanol por um período de dez anos. Trata-se de um centro virtual, com laboratórios associados que o compõem: Laboratório de Motores a Biocombustíveis (LMB), 
da Unicamp; Laboratory of Environment and Thermal Engineering (LETE), da EPUSP; Laboratório de Combustão, Propulsão e Energia (LCPE), do ITA; e Divisão de Veículos e Motores (DVM), do Instituto Mauá de Tecnologia. Waldyr Luiz Ribeiro Gallo é o responsável pelo projeto. O objetivo do projeto em andamento é explorar conceitualmente os limites de performance e eficiência para um motor dedicado a etanol, aproveitando as características peculiares desse combustível. Reflexos positivos sobre o desempenho e eficiência de motores flex também podem ser esperados.

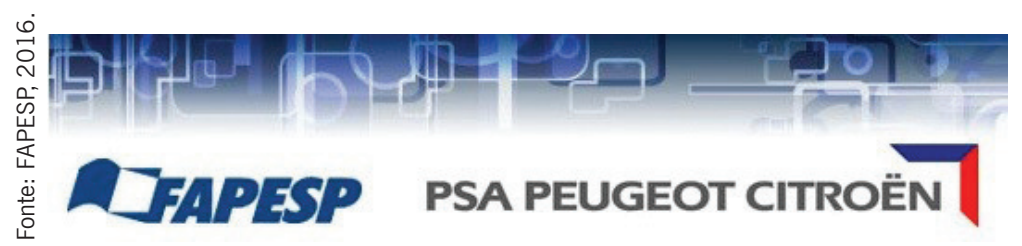

Figura 123: Projeto Fapesp PSA/Peugeot/Citroën.

\section{Fermentec lança e-book sobre seleção de leveduras}

A Fermentec publicou em 2015 o e-book Taylored Yeasts Strains for Ethanol Production: The Process Driven Selection, sobre a seleção de leveduras ${ }^{8}$. Segundo Amorim, este trabalho já de oito anos com resultados na indústria representa um marco na fermentação em escala industrial, não somente no Brasil como no mundo.

\section{Balanço de importantes contribuições do Proálcool para o Brasil}

Um resumo elaborado pelo Laboratório Nacional de Ciência e Tecnologia do Bioetanol (CTBE) sobre a evolução dos principais indicadores agroindustriais da produção de etanol de cana-de-açúcar pode ser visto na Figura 124.

8 Disponível em: <www.fermentec.com.br>. 


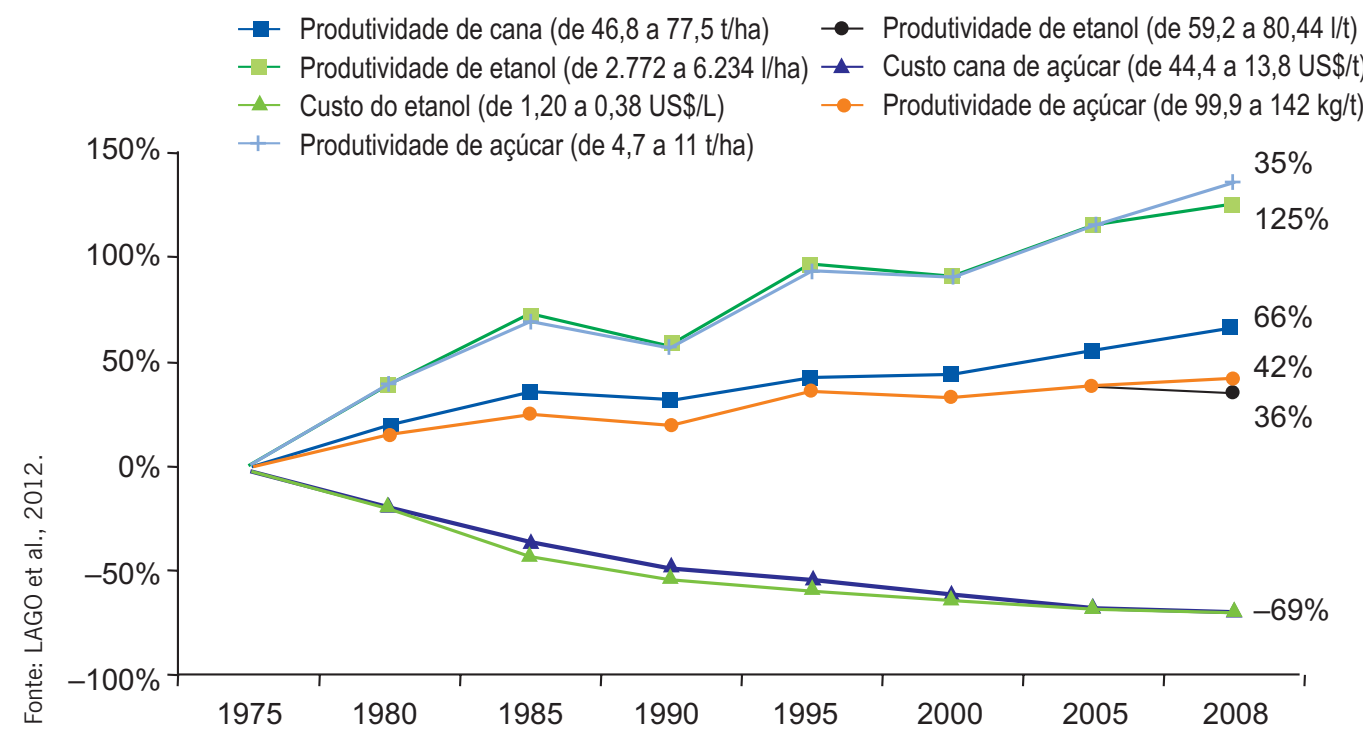

Figura 124: Crescimento da produtividade e redução dos custos de produção da cana-de-açúcar, etanol e açúcar no Brasil, de 1975 a 2008.

A evolução desses parâmetros conduziu a um aumento da competitividade do etanol de cana-de-açúcar produzido no Brasil, segundo mostra a Tabela 9.

Tabela 9: Custo de produção de etanol para diferentes matérias-primas e gasolina, em euros/100 litros

\begin{tabular}{lccccc}
\hline & $\begin{array}{c}\text { Etanol de } \\
\text { milho nos } \\
\text { EUA }\end{array}$ & $\begin{array}{c}\text { Etanol de } \\
\text { trigo na } \\
\text { Alemanha }\end{array}$ & $\begin{array}{c}\text { Etanol de } \\
\text { beterraba } \\
\text { na } \\
\text { Alemanha }\end{array}$ & $\begin{array}{c}\text { Etanol de } \\
\text { cana no } \\
\text { Brasil }\end{array}$ & $\begin{array}{c}\text { Preço da } \\
\text { gasolina em } \\
\text { Rotterdam }\end{array}$ \\
\hline Custo total de produção & 39,47 & 54,97 & 59,57 & 14,48 & 20 \\
\hline Venda de subprodutos & $-6,71$ & $-6,80$ & $-7,20$ & - & n.a. \\
\hline Subsídios de governo & $-7,93$ & - & - & - & - \\
\hline & 24,83 & 48,17 & 52,37 & 14,48 & 20 \\
\hline
\end{tabular}

Nota1: 0 custo da matéria-prima representa em todos os casos entre $50 \%$ a $70 \%$ do total do custo de produção do etanol. Fonte: Goldemberg (2011). 


\section{Segurança energética no Brasil}

O Proálcool contribuiu efetivamente para aumentar a segurança energética do país. Hoje, cerca de 18\% da matriz energética é suprida pela cana-de-açúcar, basicamente para a produção de etanol e bioeletricidade. O etanol representa cerca de $30 \%$ do combustível líquido usado em veículos leves, e a bioeletricidade representa cerca de $7 \%$ do total gerado no país. Somente com o etanol a economia de divisas entre 1975 e 2015 pode ser estimada em 300 bilhões de dólares9.

\section{Boas práticas agrícolas}

A agricultura de cana-de-açúcar muito se desenvolveu no Brasil devido à forte sintonia entre técnicos da academia e setor privado. Entre os nomes que colaboraram estão Raffaella Rossetto, do Instituto Agronômico da Agência Paulista dos Agronegócios (IAC/APTA), Hélio do Prado e Heitor Cantarella, do IAC/APTA, nas relações solo-planta, José Roberto Postali Parra, da ESALQ/USP, e Leila Luci Dinardo-Miranda, IAC/APTA, no assunto controle biológico de pragas e doenças da cana-de-açúcar e Álvaro Sanguino, do CTC, na área de doenças da cana e desenvolvimento de mudas sadias.

\section{Diminuição de emissões de GEE}

Provavelmente o trabalho cientíco mais antigo sobre a contribuição para redução de emissões de $\mathrm{CO}_{2}$ no Brasil seja o publicado por Isaías Macedo, em 1992, intitulado The Sugar Cane Agroindustry - Its Contribution to Reducing $\mathrm{CO}_{2}$ Emissions in Brazil.

A contribuição do Proálcool no que se refere à diminuição das emissões de GEE pode ser estimada considerando o volume produzido entre 1975 e 2015 de 800 bilhões de litros (20 bilhões de litros/ano $\times$ 40 anos) e $2,5 \mathrm{~kg} \mathrm{CO} /$ litro, portanto cerca de 2 trilhões de quilos de $\mathrm{CO}_{2}$. Uma avaliação mais precisa, considerando o ciclo de vida completo da produção de etanol e bioeletricidade, mostra um valor de

9 Considerando 15 bilhões de litros/ano $\times 40$ anos $\times 0,50$ cents/litro de gasolina substituído. Note-se que um cálculo mais preciso deve considerar os volumes de etanol produzidos e os valores para o câmbio corrente em cada ano. Observe-se as estimativas realizadas por Plínio Nastari, da Datagro, que constam mais adiante neste texto. 
370 bilhões de quilos de $\mathrm{CO}_{2}$ entre 1975 e 2006 (Pacca e Moreira, 2009), que, extrapolada para 2015, alcança 600 bilhões de quilos de $\mathrm{CO}_{2}$.

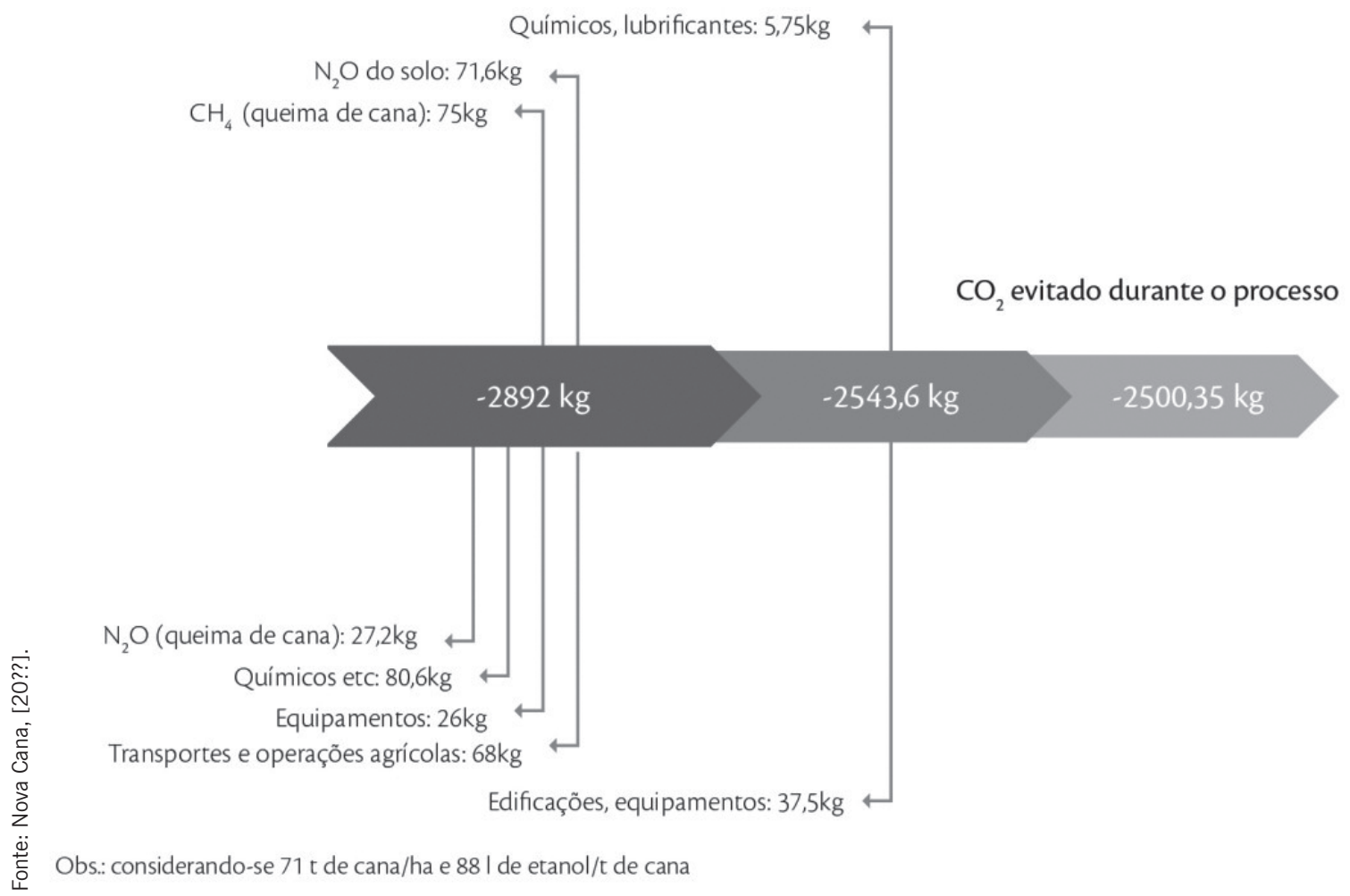

Figura 125: Balanço das emissões de $\mathrm{CO}_{2}$ eq. $\left(\mathrm{kg} \mathrm{CO}_{2}\right.$ eq. $/ \mathrm{m}^{3}$ de etanol).

Ressalte-se a importância das iniciativas internacionais sobre a sustentabilidade de biocombustíveis e a presença do Brasil nos fóruns de discussão. A Figura 126 apresenta uma lista, preparada pela Unica, das iniciativas regionais, nacionais e internacionais. 


\section{INICIATIVAS SUSTENTÁVEIS EM BIOCOMBUSTÍVEIS: Um "Universo" em constante expansão}

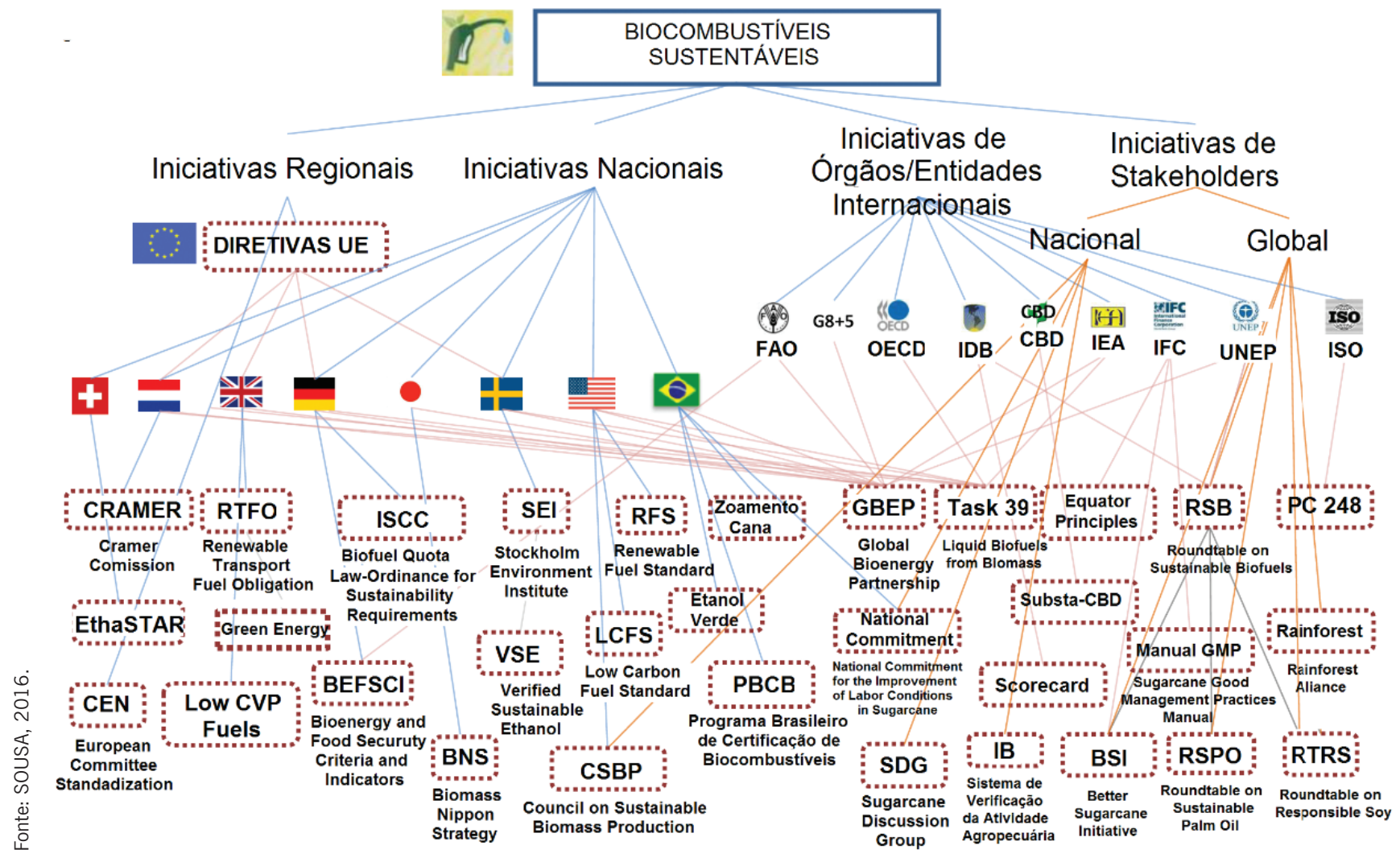

Figura 126: Iniciativas regionais, nacionais, e internacionais sobre sustentabilidade de biocombustiveis.

A Tabela 10 lista os principais indicadores utilizados para medir a sustentabilidade de biocombustíveis utilizados pelas iniciativas. Existe hoje, mais do que nunca na história, a percepção de que, além de ser economicamente viável, o biocombustível (nesse caso o etanol) deve também atender a outros requisitos, como os relativos às emissões de GEE, à não competição com a produção de alimentos e ao não comprometimento da biodiversidade. 


\section{Tabela 10: Principais indicadores utilizados para medir a sustentabilidade de biocombustiveis utilizados pelas iniciativas}

\begin{tabular}{|c|c|c|}
\hline 1 & Legalidade & Operações envolvendo biocombustíveis devem seguir todas as leis e regulações aplicáveis. \\
\hline \multirow{3}{*}{2} & $\begin{array}{l}\text { Planejamento, monitoramento e } \\
\text { melhoria contínua }\end{array}$ & $\begin{array}{l}\text { Atividades envolvendo biocombustíveis sustentáveis devem ser planejadas, implantadas e continuamente aprimoradas } \\
\text { por meio de uma Avaliação do Impacto Ambiental e Social (ESIA) aberta, transparente e consultiva e uma análise } \\
\text { da viabilidade econômica. }\end{array}$ \\
\hline & $2 a$ & $\begin{array}{l}\text { Atividades envolvendo biocombustíveis devem responsabilizar-se por uma Avaliação do Impacto Ambiental e Social } \\
\text { (ESIA) para avaliar os impactos e riscos e garantir a sustentabilidade por meio do desenvolvimento de planos de } \\
\text { implantaçãa, mitigação, monitoramento e avaliação efetivos e eficientes. }\end{array}$ \\
\hline & $2 b$ & $\begin{array}{l}0 \text { Consentimento Livre, Prévio e Informado (FPIC - Free, Prior and Informed Consent) deve formar a base para o } \\
\text { processo a ser seguido durante consultoria de todas as partes interessadas, o que deve ser sensível a gênero e resultar } \\
\text { em acordos negociados orientados pelo consenso. }\end{array}$ \\
\hline 3 & Emissões de gases de efeito estufa & $\begin{array}{l}\text { Biocombustiveis devem contribuir para a mitigação das mudanças climáticas reduzindo significativamente as emissões } \\
\text { de gases de efeito estufa do ciclo de vida em comparação aos combustíveis fósseis. }\end{array}$ \\
\hline 4 & Direitos humanos e trabalhistas & $\begin{array}{l}\text { Atividades envolvendo biocombustíveis não devem violar os direitos humanos ou os direitos trabalhistas e devem } \\
\text { promover o trabalho decente e o bem-estar dos trabalhadores. }\end{array}$ \\
\hline 5 & Desenvolvimento rural e social & $\begin{array}{l}\text { Em regiões de pobreza, atividades envolvendo biocombustíveis devem contribuir para o desenvolvimento social e } \\
\text { econômico das pessoas e comunidades locais, rurais e indígenas. }\end{array}$ \\
\hline 6 & Segurança alimentar local & $\begin{array}{l}\text { Atividades envolvendo biocombustíveis devem garantir o direito humano a alimentos adequados e melhorar a } \\
\text { segurança alimentar em regiões alimentares inseguras. }\end{array}$ \\
\hline 7 & Conservação & $\begin{array}{l}\text { Atividades envolvendo biocombustíveis devem evitar impactos negativos sobre biodiversidade, ecossistemas e outros } \\
\text { valores de conservação. }\end{array}$ \\
\hline 8 & Solo & $\begin{array}{l}\text { Atividades envolvendo biocombustíveis devem implantar práticas que buscam reverter a degradação do solo e/ou } \\
\text { manter a saúde do solo. }\end{array}$ \\
\hline 9 & Água & $\begin{array}{l}\text { Operações envolvendo biocombustíveis devem manter ou melhorar a qualidade e quantidade dos recursos aquáticos } \\
\text { da superfície e do solo, e com relação aos direitos formais e costumeiros à água. }\end{array}$ \\
\hline 10 & $\mathrm{Ar}$ & $\begin{array}{l}\text { A poluição do ar a partir de atividades envolvendo biocombustíveis deve ser minimizada ao longo da cadeia de } \\
\text { abastecimento. }\end{array}$ \\
\hline 11 & $\begin{array}{l}\text { Uso da tecnologia, informações e } \\
\text { gerencimento dos resíduos }\end{array}$ & $\begin{array}{l}\text { Os usos de tecnologias em atividades envolvendo biocombustíveis devem procurar maximizar a eficiência da produção } \\
\text { e o desempenho social e ambiental, e minimizar o risco de danos ao meio-ambiente e às pessoas. }\end{array}$ \\
\hline 12 & Direito da terra & Atividades envolvendo biocombustíveis devem respeitar os direitos da terra e os direitos do uso da terra. \\
\hline
\end{tabular}




\section{Evolução da produção de etanol em sintonia com o aumento da produção agrícola no Brasil e proteção de santuários ecológicos como a Amazônia}

É muito importante citar que a produção de etanol durante o Proálcool aconteceu ao mesmo tempo que o país viveu um aumento significativo de sua produção agropecuária (sobretudo na produção de grãos e carnes), assim como uma diminuição no desmatamento de nossas florestas. A taxa anual de desmatamento na área da Amazônia Legal nos últimos dez anos caiu em 82\% e, entre agosto de 2013 e julho de 2014, teve uma queda de 15\%, o equivalente a $5.891 \mathrm{~km}^{2}$ (Figura 127).

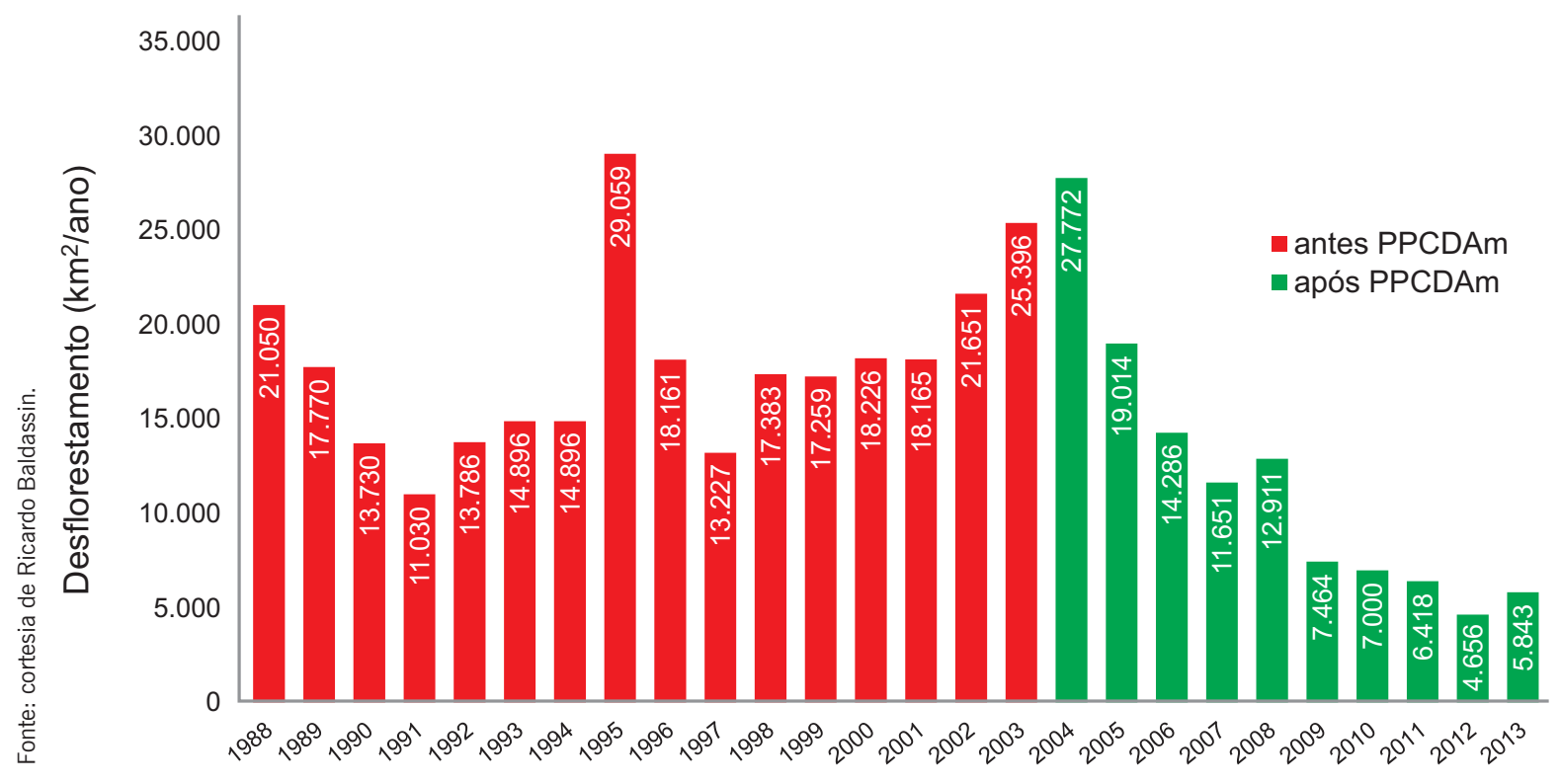

Figura 127: Taxa de desmatamento na Amazônia Legal medidas por meio do Projeto de Monitoramento do Desflorestamento na Amazônia Legal (PRODES).

Hoje, no Brasil, existe a perceção de que a expansão da produção agrícola, seja de alimentos ou de biocombustíveis, deve acontecer de forma a não comprometer a biodiversidade encontrada nas regiões da Amazônia, Pantanal, Cerrado, Mata Atlântica e outras. O país dispõe de 200 milhões de hectares de pastagens 
(pouco menos de $25 \%$ da área total) com relativa baixa produtividade ( 1 animal/hectare) e deve, portanto, racionalizar o uso do solo, principalmente por meio da intensificação sustentável da produção de gado de corte. Vale mencionar a experiência de várias usinas com integração cana-boi, como a da Vale do Rosário, em Ribeirão Preto (SP) (Taube-Netto et al., 2012).

\section{Geração de empregos e melhoraria das condições de vida no meio rural}

Outro impacto importante do Proálcool se deu no estímulo à economia, sobretudo rural, e na geração de empregos. As atividades que compõe o setor sucroalcooleiro chegaram a gerar cerca de 1 milhão de empregos. Depois, com a adoção da colheita de cana-de-açúcar crua (sem queimar), muitas usinas introduziram a colheita mecanizada, o número de empregos rurais diminuiu, felizmente em uma época em que o setor crescia rapidamente, absorvendo de alguma maneira essa mão-de-obra em atividades mais produtivas. Os avanços nessa área de estudo podem ser vistos por meio dos trabalhos de Márcia Azanha Ferraz Dias de Moraes, da ESALQ/USP.

\section{Veículos a álcool e veículos flex: um mercado único no mundo}

A evolução do mercado de etanol combustível no Brasil foi impressionante nestes últimos quarenta anos. Mais do que qualquer outro país no mundo, empresários, cientistas e a própria sociedade se empenharam para concretizar a sustituição da gasolina por um combustível renovável e produzido localmente. Nas diferentes fases do Proálcool, o etanol combustível viveu três momentos distintos, como mostra a Figura 128. Em um primeiro momento, até 1989, prevaleveu o uso de etanol em carros a álcool (hidratado) e a mistura do etanol anidro à gasolina. Em um segundo momento, após a crise de 1989 até 2002, prevaleceu o declínio e o desaparecimento do carro a álcool, e aumento das quantidades de etanol anidro na mistura. Por último, o período de 2002 até hoje foi marcado pela introdução do carro flex-fuel no país. 


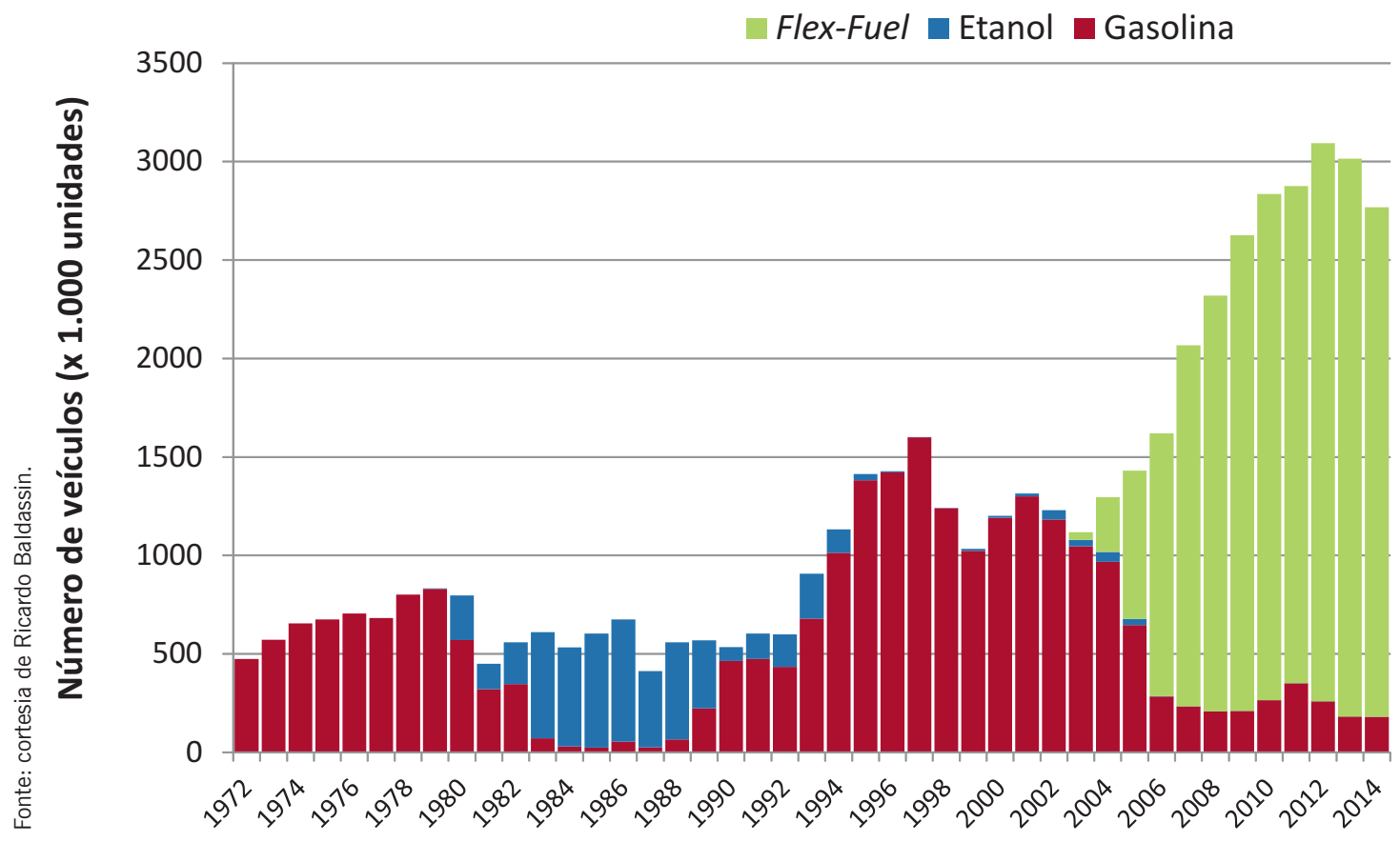

Figura 128: Evolução dos veículos leves no Brasil quanto ao tipo de combustível utilizado.

0 Proálcool como exemplo para outros países em desenvolvimento de como diminuir a dependência energética sem comprometer a segurança energética, alimentar e a biodiversidade ${ }^{10}$

Muitos países olham o Proálcool como um exemplo a ser seguido, considerando-o um programa que os atrai mais pelo desenvolvimento do que pela segurança energética. Esse interesse pode ser observado na América Latina, na Ásia e na África, principalmente por parte de países, como Moçambique, por exemplo, que, embora possuam grandes reservas de carvão mineral, se interessam pelo etanol de cana pelos possíveis impactos sociais.

10 Mais sobre o assunto nas publicações do Worldwatch Institute, Biofuels for Transport (2007) e Bioenergy for Sustainable Development and International Competitiveness: The Role of Sugar Cane in Africa, do Stockholm Environment Institute (SEI). 


\section{Segurança energética e bioeconomia}

O Brasil é provavelmente o país que tem maior participação relativa da biomassa moderna em sua matriz energética e também o país com maior potencial para expandir essa participação. $O$ equacionamento da questão energética no século XXI dependerá, em cada país, do potencial de cada fonte energética, e por esta razão a "solução energética" de um dado país dificilmente poderá ser transplantada para outro. Assim, o potencial brasileiro para energia solar, eólica e, sobretudo, bioenergia não pode ser desprezado ou desconsiderado, principalmente em um momento da história em que os gases que provocam o chamado "efeito estufa" (GEE) são considerados tão importantes. No seu balanço das emissões de $\mathrm{CO}_{2}$, o etanol de cana-de-açúcar produzido no Brasil tem um potencial considerável de mitigação de GEE. Portanto, mesmo explorando as riquezas do petróleo do pré-sal, o país deveria valorizar seu potencial para a produção de bioenergia.

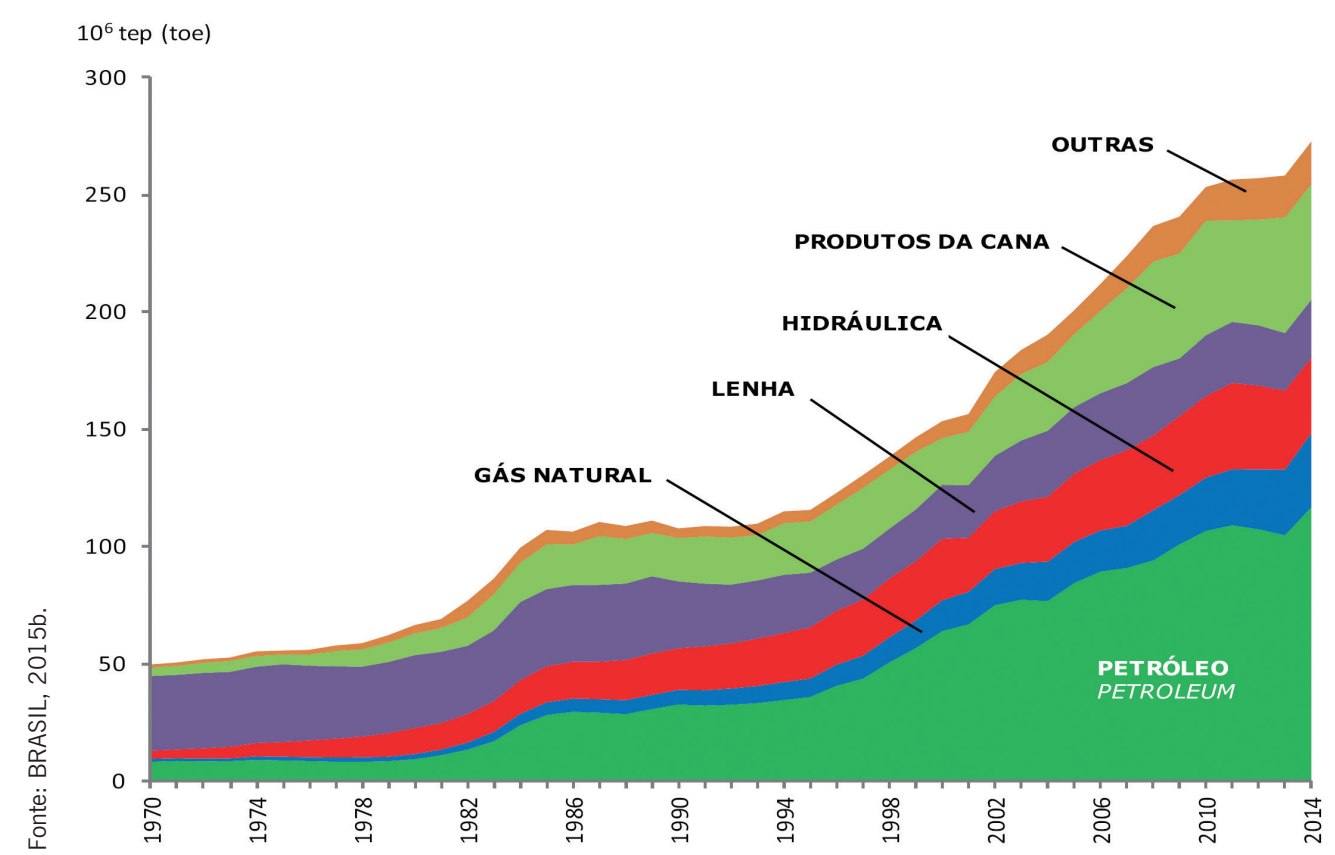

Figura 129: Participação das fontes primárias na matriz energética brasileira. 


\section{Expandindo o uso de bioenergia na América Latina e África (a "diplomacia do etanol")}

De acordo com Doornbosch e Steenblik (2007), 60\% das terras potencialmente disponíveis do total mundial poderiam ser usadas na produção de bioenergia em 2050 (440 Mha), das quais cerca de 60\% (250 Mha) estariam na América Latina e Caribe e 40\% (180 Mha) na África. A maior disponibilidade de terras para a bioenergia seria, em grande parte, originária de terras com pastagens. Por outro lado, vários países em desenvolvimento poderiam se beneficiar da experiência brasileira de produção de etanol de cana-de-açúcar, visando aumentar sua segurança energética.

Vários países latino-americanos e africanos possuem programas de produção de etanol e biodiesel. Entre eles citam-se os casos da Colômbia, Argentina, Paraguai e Malawi. A Colômbia, por exemplo, já mistura $10 \%$ de etanol na gasolina e $5 \%$ de biodiesel no diesel. É um país com grandes quantidades de terras aptas ao cultivo agrícola e ainda inexploradas.

A fim de estudar em mais detalhe a expansão da produção de biocombustíveis na América Latina e África, foi montado o Projeto LACAf-cana, coordenado por Luís Cortez, Luiz Augusto Horta Nogueira, Edgar Beauclair e Manoel Regis Lima Verde Leal, com foco no estudo de quatro países: Colômbia, Guatemala, África do Sul e Moçambique. Alguns resultados desse projeto são mostrados na Figura 130.

O objetivo do projeto LACAf-cana é colaborar com o Global Sustainable Bioenergy Project (GSB), cuja meta é testar a hipótese de que é fisicamente possível para a bioenergia atender sustentavelmente uma fração substancial da futura demanda energética ( $\geq 25 \%$ da mobilidade global ou equivalente em 2050), ao mesmo tempo que produz os alimentos necessários e atende outras necessidades de terras, preservando o habitat da vida selvagem e mantendo a qualidade ambiental (ver detalhes mais adiante no texto, na seção sobre a Internacionalização da Cooperação Científica da Bioenergia).

Sabe-se que na maioria dos países em desenvolvimento a questão central é a inclusão energética (acesso a combustíveis modernos e eletricidade) e que as soluções são sempre de natureza multidisciplinar, envolvendo aspectos técnicos, econômicos, sociais e ambientais.

Ressalte-se igualmente os estudos da diplomacia do etanol brasileiro, os esforços conduzidos pela Fundação Getúlio Vargas (FGV) sobre o potencial de produção de etanol em países africanos. 


\section{LACAF DFAPESP Produção de cana-de-açúcar na} Colômbia

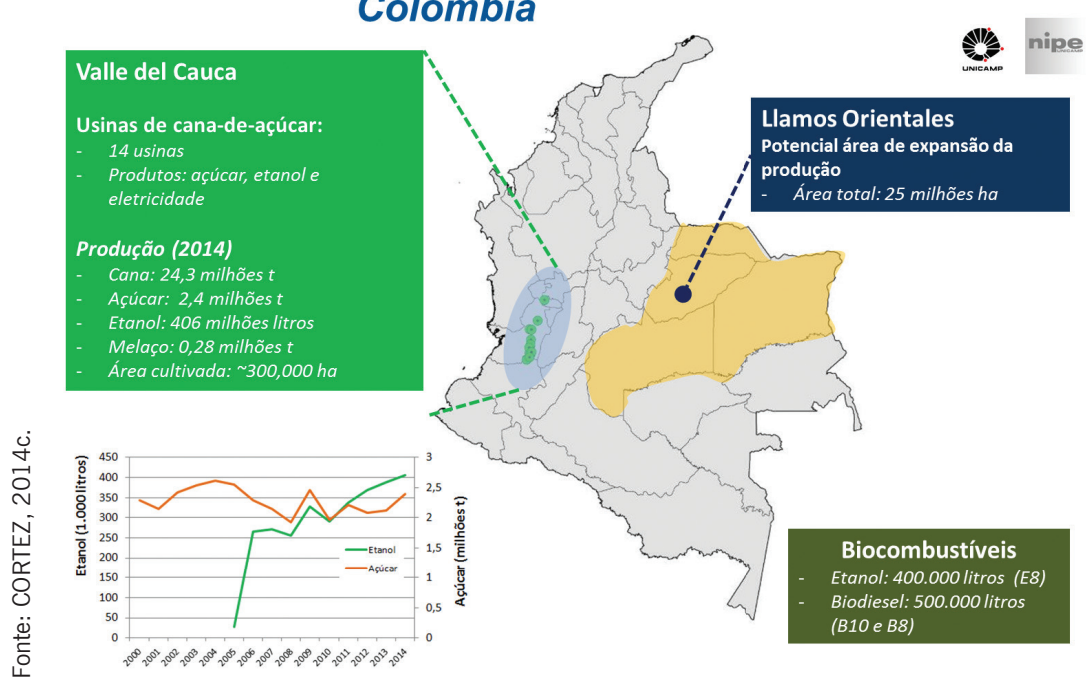

(a)

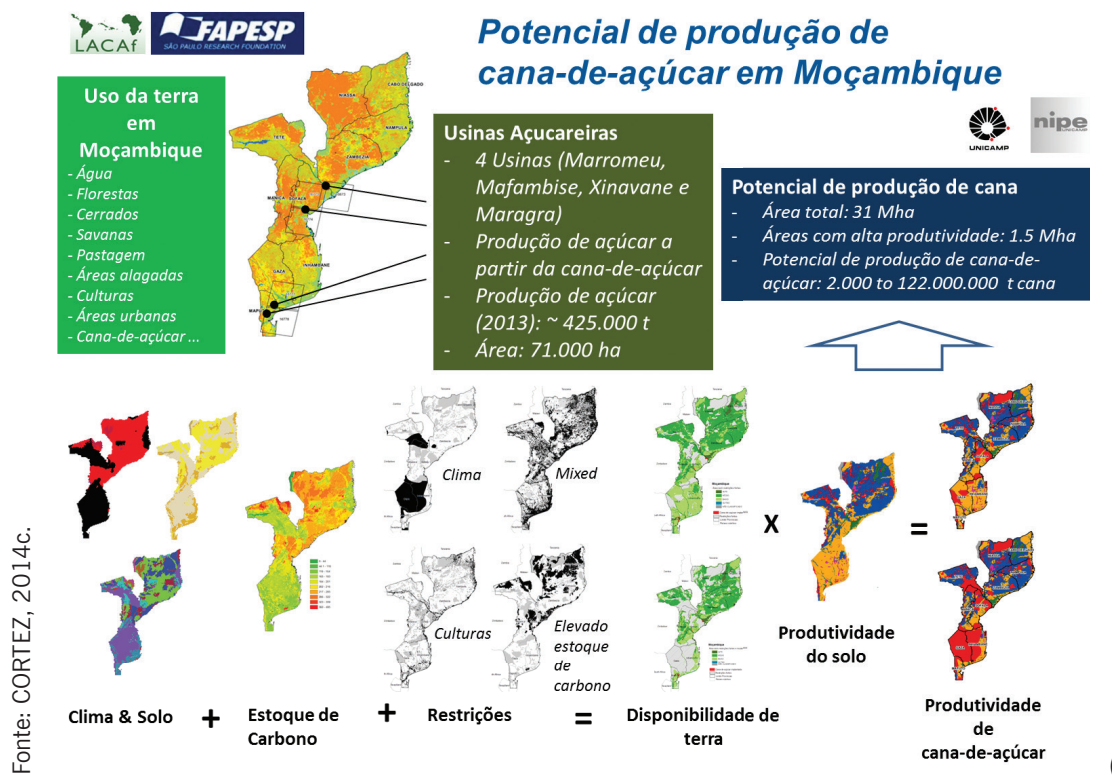

Figuras 130a e 130b: Projeto LACAf - potenciais de produção de bioenergia de cana-de-açúcar na América Latina, Caribe e África. 
Valem ser destacadas, igualmente, as ações do Ministério das Relações Exteriores (MRE) no apoio à "diplomacia do etanol". Estima-se que o Itamaraty tenha formalizado mais setenta acordos bilaterais de cooperação no tema do etanol, principalmente na última década, envolvendo diversas embaixadas brasileiras ${ }^{11}$.

\section{A busca do mercado externo para o etanol brasileiro}

O etanol brasileiro tentou buscar novos mercados a partir da sua consolidação no mercado interno. No início da década de 1980 já se falava em exportação e se faziam estudos sobre o tema. Sergio C. Trindade, na SE2T International, nos últimos 24 anos, realizou projetos exitosos ${ }^{12}$ nessa direção para Copersucar, Unica, MDICE, Brenco e outros, tais como:

1) A política brasileira de comércio internacional de etanol, inclusive para o conceito da parceria com os EUA para promover terceiros mercados; o desenvolvimento de mercados de futuros e opções; roadmap de pesquisa e desenvolvimento; necessidade de desenvolver infraestrutura de transporte, armazenamento e portos para a expansão do etanol combustível etc.

2) A abertura do mercado americano, começando pela Califórnia, para o etanol de origem brasileira, diretamente e via desidratação no Caribe.

3) A abertura do mercado chinês de etanol combustível importado pela redução da tarifa de importação, em consequência de trabalho desenvolvido para a Brenco.

4) O programa de biocombustíveis do México, em trabalho patrocinado pelo BID, em conjunto com Horta Nogueira e Isaías Macedo.

No estudo de Leite et al. (2009) sobre a substituição de $\mathbf{1 0 \%}$ da gasolina do mundo por etanol de canade-açúcar, já citado, fica claro o potencial de produção. No entanto, as quantidades exportadas de etanol brasileiro têm sido relativamente pequenas, sobretudo a partir de 2009 quando o país teve que importar o combustível. Na Figura 131, são mostradas as quantidades comercializadas de 2004 a 2014.

11 Mais sobre os últimos 40 anos do Proálcool, contribuições e perspectivas futuras podem ser encontradas em BNDES (2008), Unica (2012a), Unica (2012b) e Walter et al. (2014).

12 Comunicação de Sergio C. Trindade. 


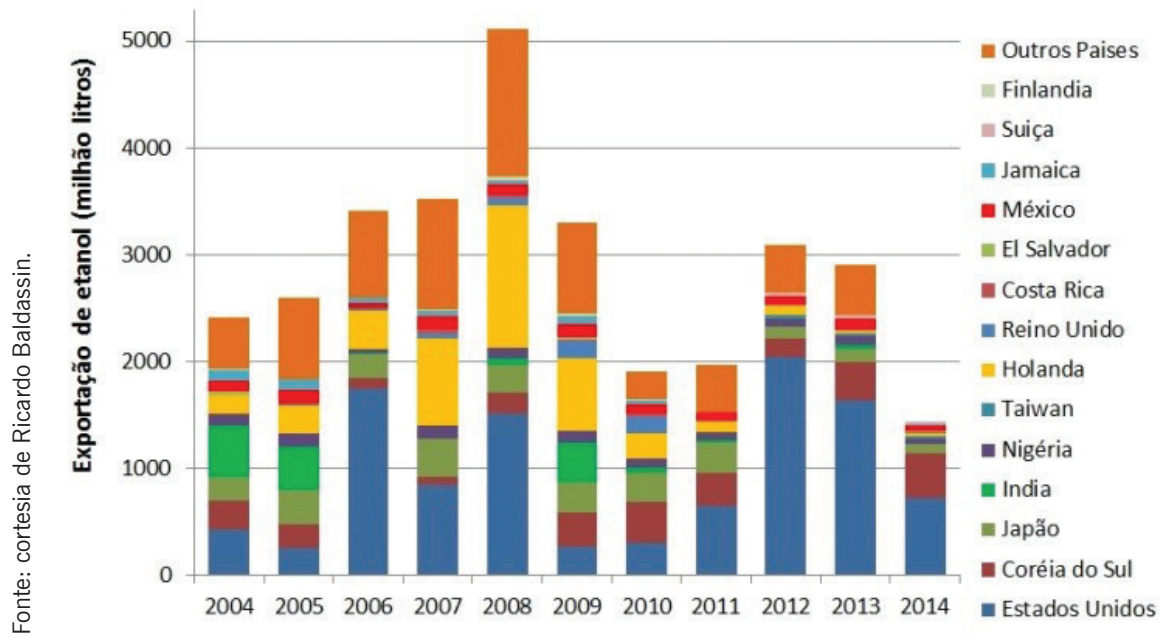

(a)

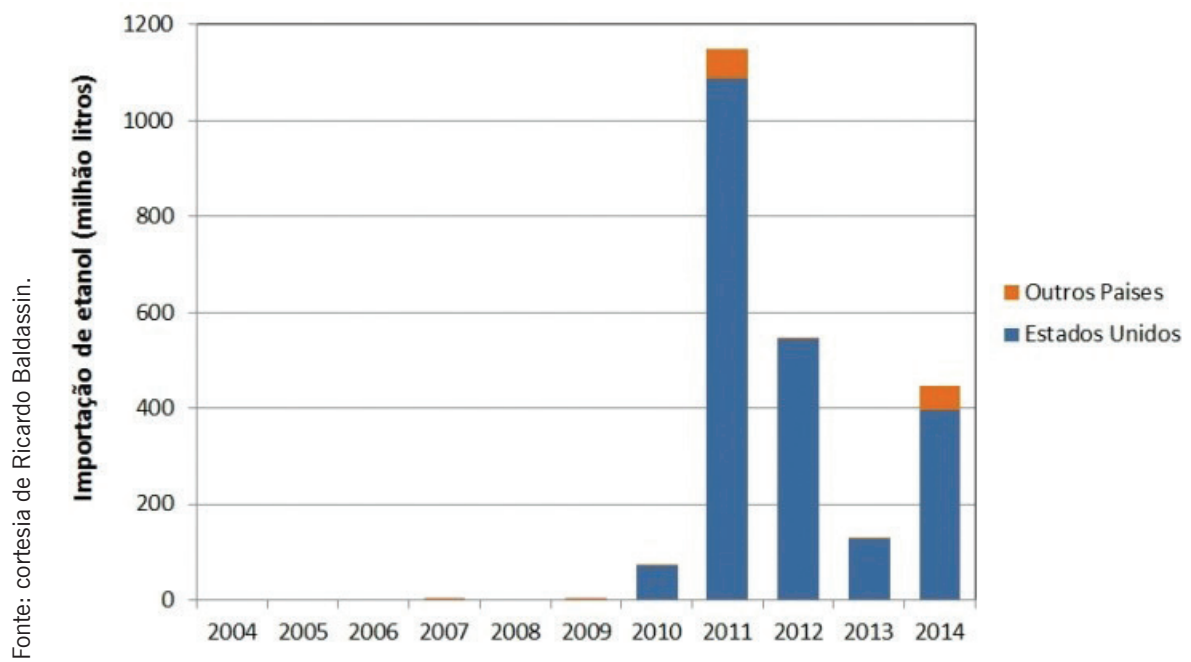

Figuras 131a e 131b: Exportação e importação de etanol pelo Brasil.

Em relação aos países e suas respectivas políticas para o comércio de etanol, estas sempre estiveram sujeitas às flutuações dos preços internacionais do petróleo, às políticas ambientais, especialmente de qualidade do ar, e à proteção de seus mercados domésticos, com pouca percepção da urgência em relação 
ao impacto dos GEE nas mudanças climáticas. Na Figura 132, são mostrados os volumes do comércio global de etanol combustível.

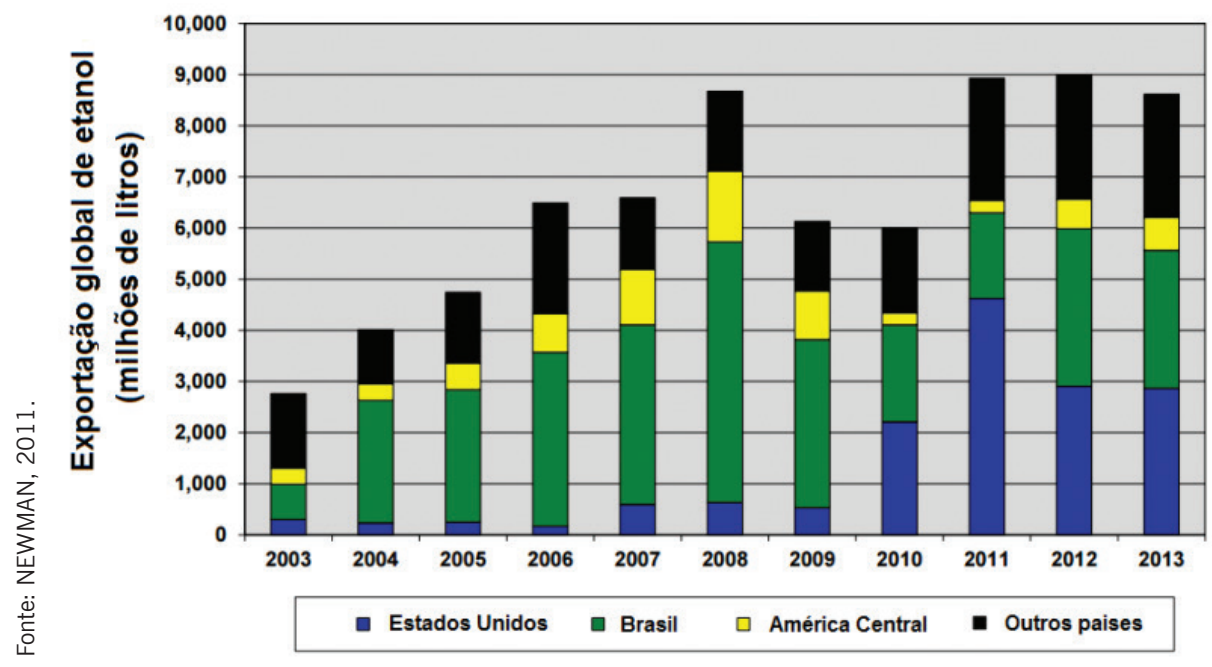

(a)

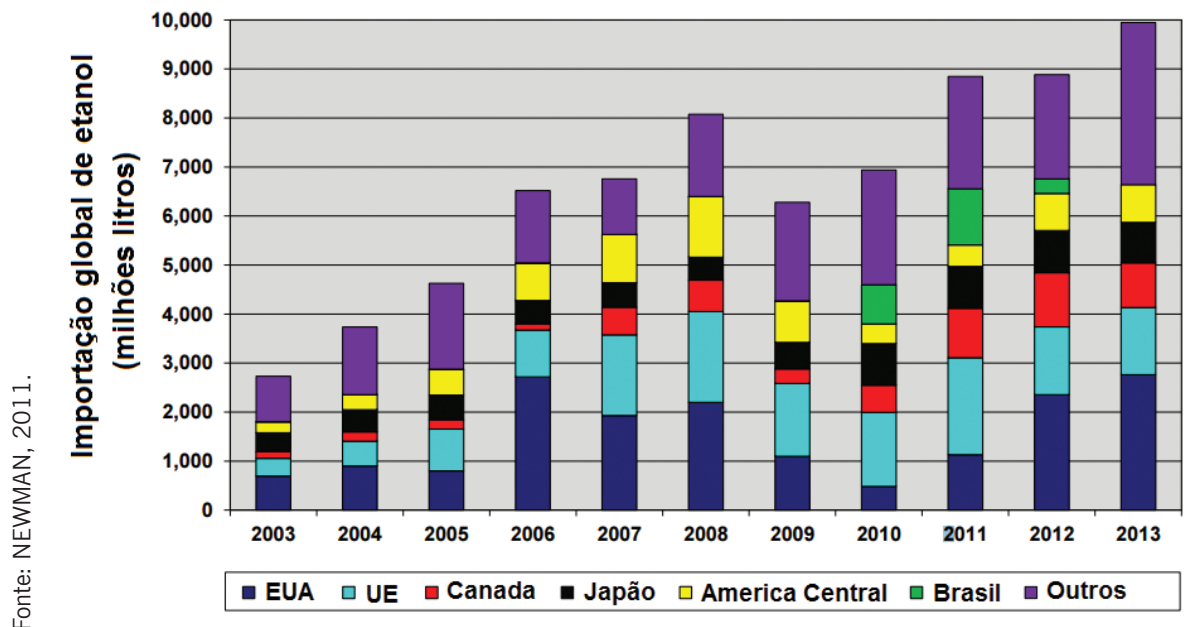

(b)

Figuras 132a e 132b: Comércio global de etanol combustivel. 
Nesse contexto, sempre houve barreiras ao comércio de biocombustíveis, especialmente bioetanol, que se acentuaram ao longo do tempo, principalmente nos mercados europeu e norte-americano. Este último foi finalmente aberto a partir de 2012, devido, em parte, aos esforços da Unica.

Sendo os EUA e o Brasil os dois principais países produtores e consumidores, ambos têm especial responsabilidade para a promoção do mercado internacional e também da colaboração científica, tecnológica e empresarial. Isso foi finalmente implementado em 2007 por meio de acordo bilateral Brasil-EUA, visando promover terceiros mercados, incrementar o comércio e o desenvolvimento tecnológico. Na Figura 133a, é mostrado o comércio de etanol entre o Brasil e os EUA de 2004 a 2014.

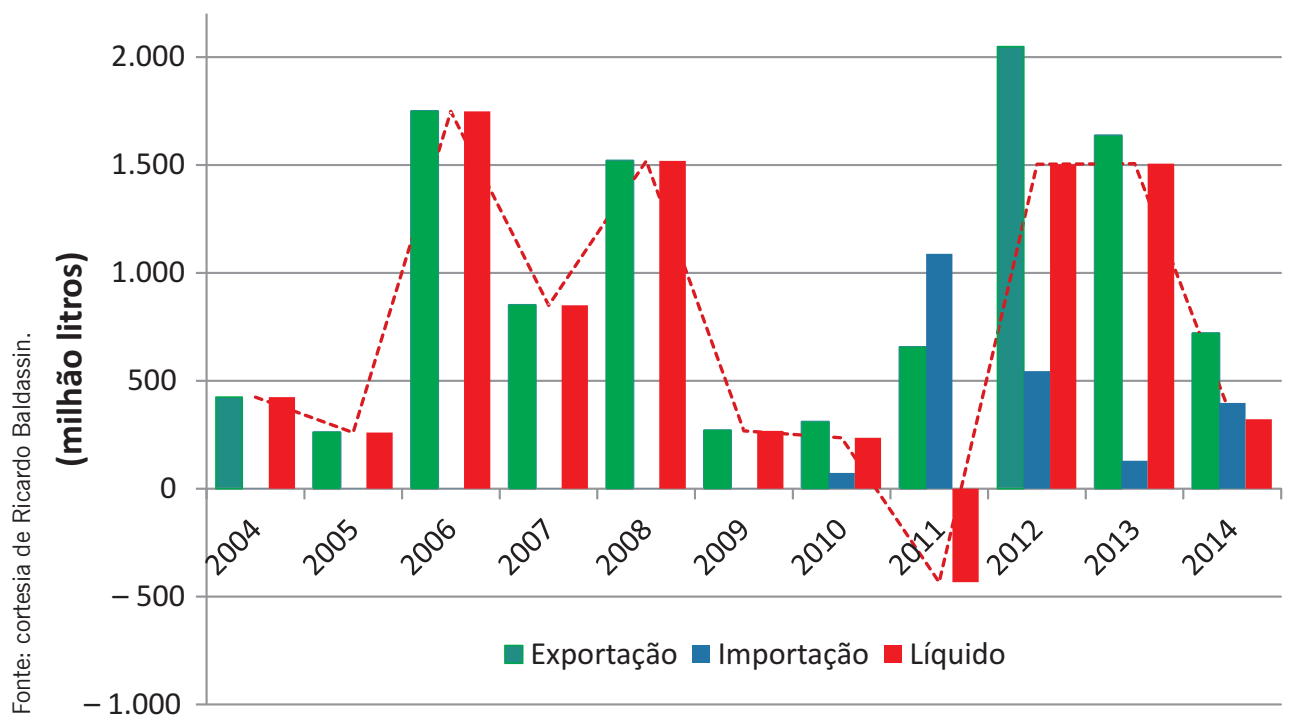

Figura 133a: Comércio de etanol entre Brasil e EUA, de 2004 a 2014.

O mercado de etanol no mundo e seus principais países produtores estão na Figura 133b. 


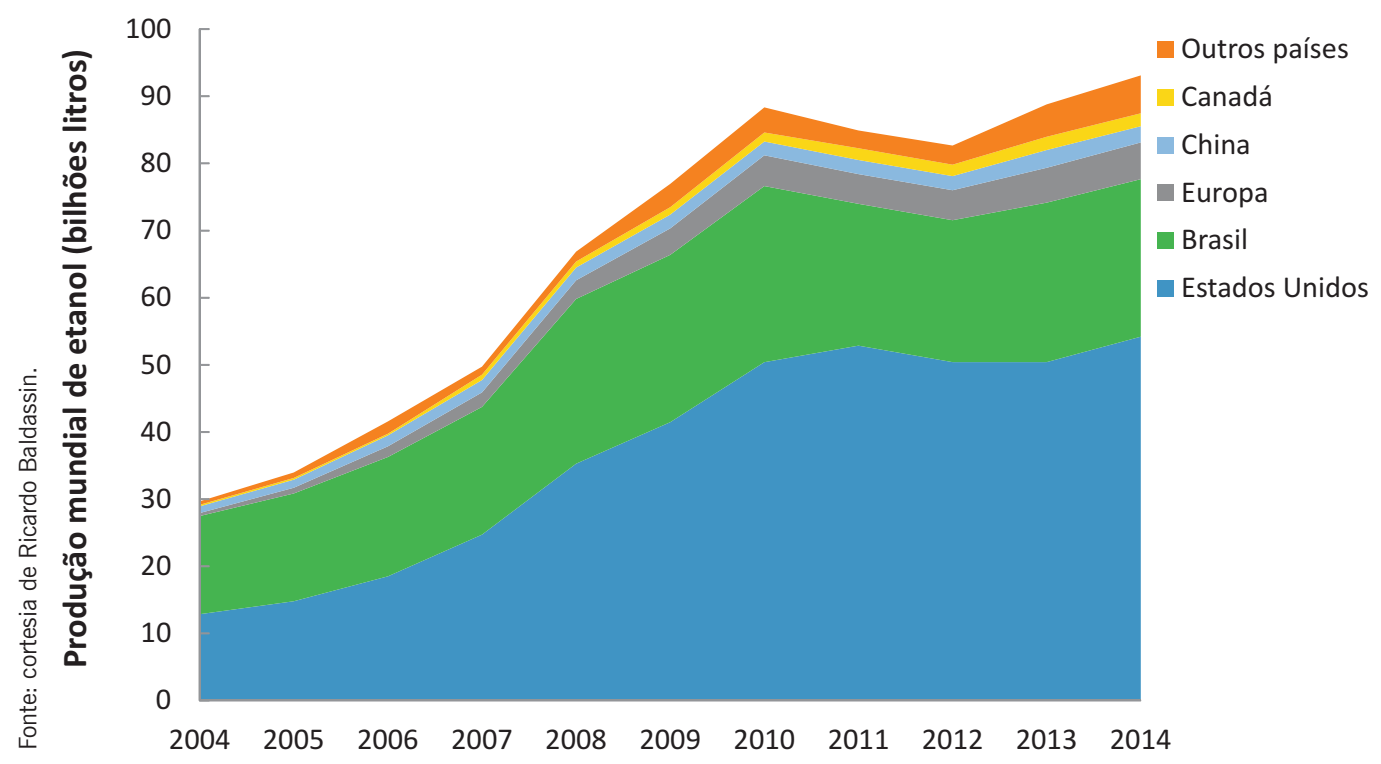

Figura 133b: Produção de etanol entre 2004-2014 pelos principais países produtores.

\section{A internacionalização da cooperação científica para a bioenergia}

Muitos foram os pesquisadores e as instituições internacionais que, ao longo destes quarenta anos, interagiram com a comunidade científica brasileira nos diversos temas do etanol combustível, contribuindo em muito para o sucesso do Proálcool.

Uma das instituições que muito contribuíram para a ciência e tecnologia do setor sucroalcooleiro foi a International Society of Sugar Cane Technologistics (ISSCT), fundada em 1924. A ISSCT realizou 28 congressos internacionais, dos quais três no Brasil, sempre em São Paulo $(1977,1989 \text { e } 2013)^{13}$.

13 Ver $<$ www.issct.org/\#>. 
Uma das primeiras contribuições internacionais sobre o Proálcool veio da visita de Francisco Rosillo-Calle (Figura 134) ao Brasil, em 1981. Em sua tese de doutorado na Inglaterra, no início da década de 1980, ele explicava como o Brasil se organizou institucionalmente para montar o Proálcool. Rosillo-Calle também publicou outros livros tratando de bioenergia no Brasil, entre eles The Charcoal Dilemna: Finding a Sustainable Solution for Brazilian Industry e Uso da biomassa para produção de energia na indústria brasileira.

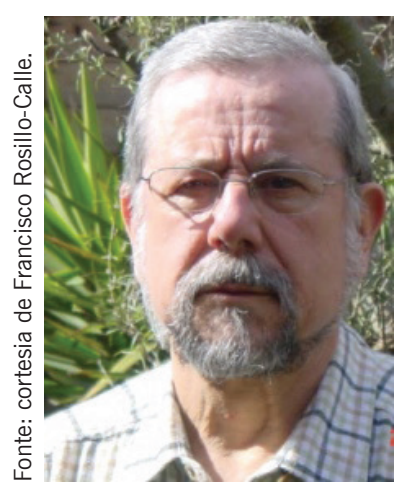

Figura 134: Francisco Rosillo-Calle.

\section{8: criação do International Consortium for Sugarcane Biotechnology (ICSB)}

Este consórcio é um exemplo de cooperação internacional para alavancar recursos e conhecimentos dos participantes do setor em busca de um objetivo comum. O ICSB é composto por dezessete instituições-membros de doze países. Entre os membros estão o CTC e o Sugar Research Australia (SRA).

\section{5: acordo BC/CAPES em biomassa moderna}

Em 1995, David Hall (King's College, Figura 135) e Sérgio Bajay (Unicamp) iniciaram uma colaboração, fruto de um projeto British Council/CAPES, objetivando estudar as três principais indústrias brasileira na área de biomassa: siderúrgica com o carvão vegetal, papel e celulose com o eucalipto, e sucroalcooleira com a cana-de-açúcar. Desse projeto resultou o livro Industrial Uses of Biomass Energy: The Example of Brazil.

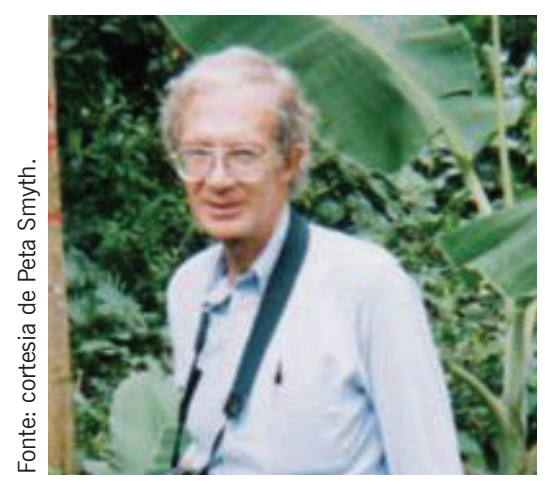

Figura 135: David Hall. 


\section{8: início da parceria com o NREL}

Em 1998, Helena Chum (National Renewable Energy Laboratory-NREL, Figura 136) e Isaías Macedo (Unicamp) iniciaram colaboração na área de bioenergia moderna. As atividades do NREL em tecnologias avançadas de hidrólise e termoconversão e também sustentabilidade de biocombustível estimularam o acordo, que veio a possibilitar um grande intercâmbio de pesquisadores.

\section{Década de 1990: primeiras redes de biocombustiveis e a promoção da bioenergia na América Latina}

Estudos coordenados por Luiz Augusto Horta Nogueira, da UNIFEI (Figura 137), sobre o quadro atual e as perspectivas dos biocombustíveis na América Latina, levaram à criação da Red de Cooperación en Dendroenergia, da Organização das Nações Unidas para Alimentação e Agricultura (FAO), reunindo profissionais de instituições de diversos países e promovendo intercâmbio de conhecimento e experiências. Posteriormente, Horta desenvolveu outros trabalhos: a) para a CEPAL, desde 2004, diversos estudos sobre o potencial e as condições para promover a produção e uso de etanol de cana de açúcar nos países da América Central, posteriormente

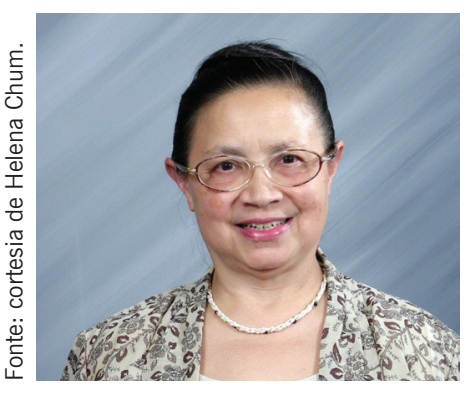

Figura 136: Helena Chum.

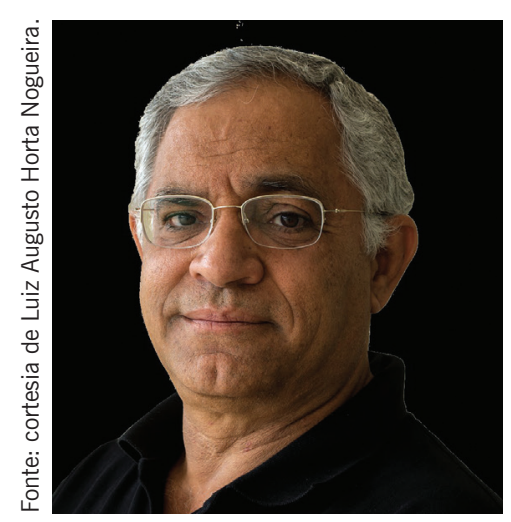

Figura 137: Luiz Augusto Horta Nogueira. detalhados para a Guatemala e Costa Rica; estudos sobre a bioenergia em países da América Andina e Guyana; e estudos sobre os aspectos econômicos e institucionais para promover os biocombustíveis na América Latina; b) para o BID em 2007, com Isaías Macedo e Sergio C. Trindade, um amplo estudo visando à implantação de um programa de biocombustíveis no México; e c) para instituições como a Universidad Católica de Chile e a Universidad Tecnológica Nacional da Argentina, ministrando cursos sobre bioenergia.

Essas atividades, bem como a participação em muitos encontros regionais sobre bioenergia e biocombustíveis, foram oportunas para as atividades da Cátedra do Memorial da América Latina, que objetivava estudar e promover os biocombustíveis sustentáveis nessa região. 


\section{5: parcerias com o Royal Institute of Technology (KTH) da Suécia}

Semida Silveira (Figura 138), brasileira radicada em Estocolmo, na Suécia, colaborou formando doutores na área de bioenergia do etanol e também publicou o livro Bioenergy - Realizing the Potential, com vários autores brasileiros. A contribuição do seu time no KTH inclui metodologias para análise do balanço energético e emissões de gases de efeito estufa, otimização do uso de recursos da biomassa, bem como análise de políticas públicas e formação de mercado para o etanol em nível nacional e internacional.

\section{5: parcerias em hidrólise com a Lund University, da Suécia}

Uma importante parceria se estabelece com Guido Zacchi (Figura 139), da Lund University, na Suécia. Zacchi, uma das maiores autoridades em hidrólise, veio ao CTBE e ajudou na construção do programa do etanol lignocelulósico.

\section{9: The Global Sustainable Bioenergy - o GSB Project ${ }^{14}$}

Em 2009, iniciou-se o Projeto GSB, trazido por Lee Lynd (Figura 140), professor do Dartmouth College, nos EUA. A meta do projeto era chegar a 2050 com pelo menos $25 \%$ da matriz energética mundial composta por bioenergia sustentável. Para tanto, inicialmente, foram realizadas cinco convenções continentais visando responder às três perguntas básicas do Projeto GSB: por que produzir bioenergia?; Quanto é possível produzir?; e Como, de que maneira, deve-se produzir bioenergia?

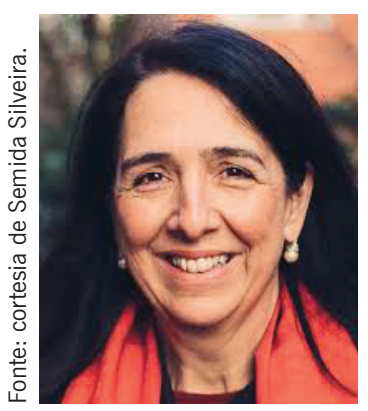

Figura 138: Semida Silveira.

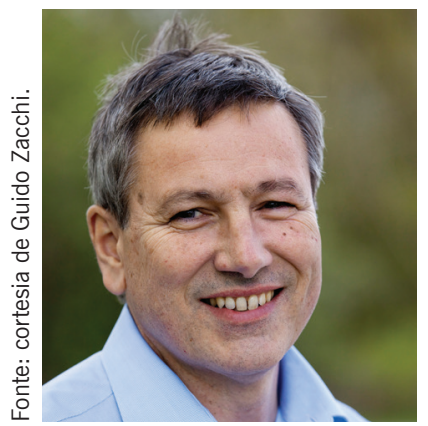

Figura 139: Guido Zacchi.

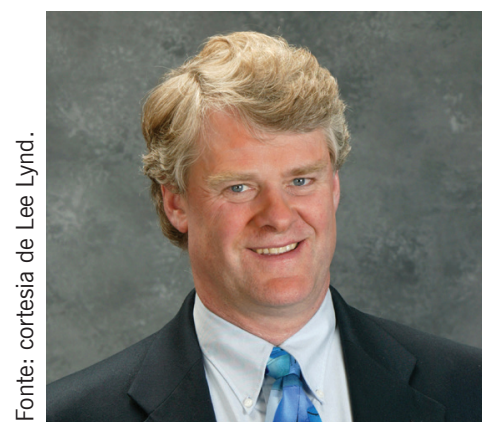

Figura 140: Lee Lynd.

14 Ver <www.fapesp.br/5583>. 
Essas questões estão sendo hoje trabalhadas em projetos temáticos para a América Latina e África, regiões que detêm o controle das terras ainda disponíveis, mas onde existem problemas relacionados com segurança alimentar, energética, além da fragilidade política-institucional. Além desse projeto há também outro temático que estuda a intensificação de pastagens visando permitir o uso de terras para a produção de bioenergia. O projeto GSB se desenvolve com o apoio da Fapesp, contando com a colaboração de outros pesquisadores do exterior, como John Sheehan, da University of Colorado, Jeremy Woods, do Imperial College, e Keith Kline e Virginia Dale, ambos do Oak Ridge National Laboratory (ORNL).

\section{Grupo de Economia Agrícola da ESALQ/USP}

Um grupo muito atuante na área de economia internacional é o da ESALQ/USP, que há pelo menos duas décadas tem coletado e organizado informações sobre a evolução do setor sucroalcooleiro, a partir das quais se desenvolvem pesquisas que subsidiam a condução de políticas econômicas e comerciais. Vários pesquisadores deste grupo se destacam, entre eles, Marcos Jank, que recentemente foi presidente da Unica, e Heloisa Lee Burnquist.

\section{1: a Fapesp inicia a realização de uma série de workshops de cooperação científica chamados Fapesp Week}

São realizados vários workshops de cooperação envolvendo universidades, centros de pesquisa em várias áreas, incluindo bioenergia. Já foram realizados Fapesp Weeks nas seguintes locais: Washington (2011), Toronto (2012), Cambridge (2012), Washington (2012), Morgantown (2012), Salamanca (2012), Madri (2012), Carolina do Norte (2013), Londres (2013), Tóquio (2013), Califórnia (2014), Munique (2014), Pequim (2014), Barcelona (2015), Davis (2015) e Buenos Aires (2015).

\section{3: acordo Fapesp-Nepad}

A Fapesp assinou um acordo com o New Partnership for Africa Development (Nepad - Figura 142) para cooperação no campo da promoção da bioenergia sustentável na África. 


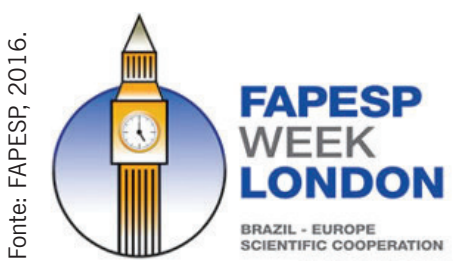

Figura 141: Fapesp Week.

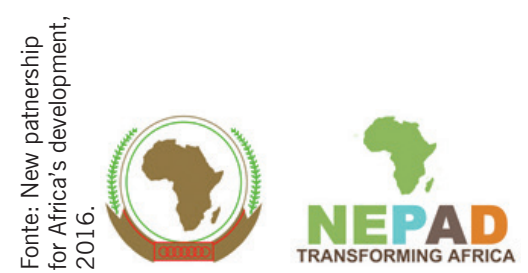

Figura 142: Nepad.

\section{3: BE-Basic inicia colaboração visando "bioeconomia"}

Em 2013, a BE-Basic Foundation vem ao Brasil para promover a bioeconomia. A BE-Basic é uma parceria público-privada internacional que desenvolve soluções industriais de base biológica para construir uma sociedade sustentável. A ideia é mudar o paradigma de combustíveis fósseis para biomassa moderna, desenvolvendo novas tecnologias e conhecimentos para todas as indústrias de alimentos, produtos químicos, energia e materiais.

O BE-Basic tem estimulado a colaboração entre o meio acadêmico e a indústria, entre cientistas e empresários e entre os Países Baixos e outros países, com ênfase na colaboração. Luuk van der Wielen (Figura 144), da Delft University of Technology (DUT), é o gerente do BE-Basic. Entre as ações atuais há o curso de graduação/pós-graduação/extensão DUT/Unicamp sobre biocombustíveis. Os projetos do BE-Basic contam com o apoio de Patricia Osseweijer, também da Delft University of Technology (DUT) Gustavo Paim Valença e Telma Franco (FEQ/UNICAMP).

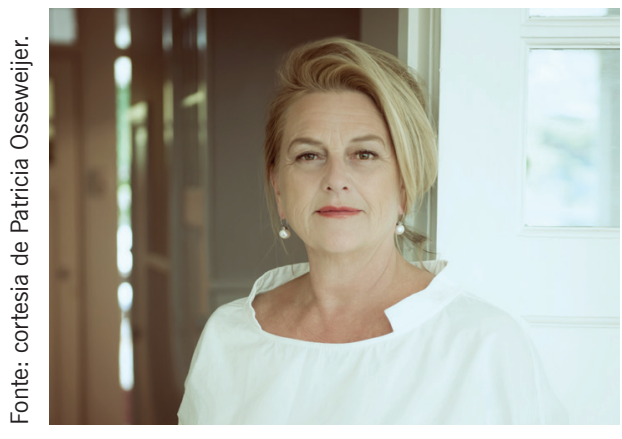

Figura 143: Patricia Osseweijer.

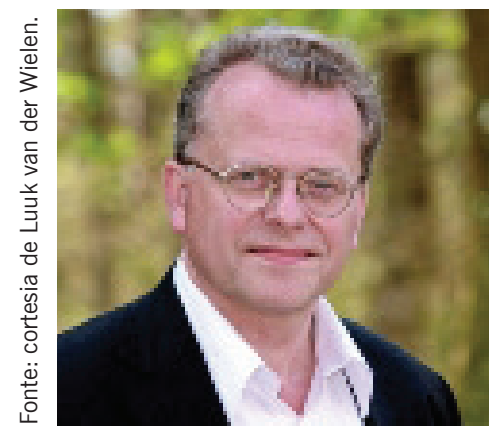

Figura 144: Luuk van der Wielen. 


\section{4: a cooperação internacional no CTC}

O Centro de Tecnologia Canavieira (CTC) sempre contou com consultores internacionais que ficaram vivendo certo tempo no Brasil. Entre os pesquisadores estrangeiros podem ser citados Albert J. Mangelsdorf e Paul H. Moore (Figura 145), ambos do Havaí, entre outros.

\section{4: BIOEN/Fapesp organiza o Relatório Scope conclusivo sobre Sustentabilidade da Bioenergia}

O Relatório do Scientific Committee on Problems of the Environment (Scope $)^{15}$ Bioenergy \& Sustainability é uma das contribuições científicas mais importantes na área de sustentabilidade em bioenergia. Coordenado por Gláucia Mendes Souza (BIOEN/ Fapesp), Reynaldo Vitória (Mudanças Climáticas/Fapesp), Carlos Joly (Biota/Fapesp) e Luciano Verdade, o relatório com mais de 700 páginas foi publicado em 2015 e é resultado do esforço de 137 pesquisadores de 82 instituições e 24 países, tratando das principais questões relativas à sustentabilidade de biocombustíveis, incluindo segurança alimentar, segurança energética, ambiental, desenvolvimento econômico e inovação (Figura 146).

Com base em mais de 2 mil referências e estudos importantes, o relatório fornece uma análise global do panorama atual da bioenergia, tecnologias e práticas com uma revisão crítica dos seus impactos. Considera uma ampla avaliação do atual status dos recursos bioenergéticos, sistemas e mercados e o potencial de expansão sustentável desse recurso renovável.

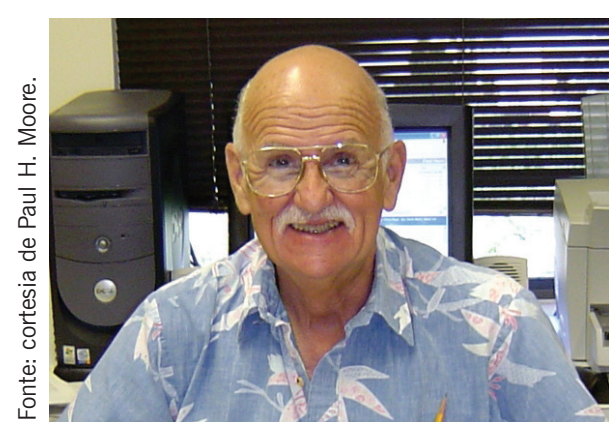

Figura 145: Paul H. Moore.

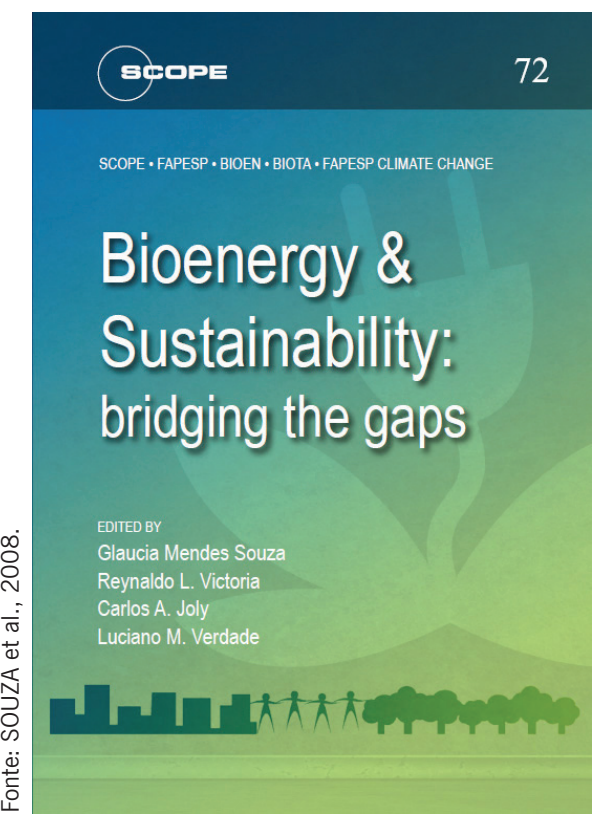

Figura 146: Relatório Scope.

15 Disponível em: <http://bioenfapesp.org/scopebioenergy/images/chapters/bioenergy_sustainability_scope.pdf >. 
Os autores fazem recomendações para a política e implantação de opções de bioenergia: biocombustíveis líquidos, bioeletricidade, biogás, calor e produtos químicos de base biológica.

Os autores consideraram a expansão da bioenergia e os seus impactos no domínio da energia, alimentos, segurança ambiental e climática, desenvolvimento sustentável e o nexo da inovação nas regiões desenvolvidas e em desenvolvimento no mundo. O relatório também destaca números, soluções, lacunas no conhecimento e sugere a ciência necessária para maximizar os benefícios de bioenergia.

Painéis incluíram especialistas da academia, da indústria e das ONGs, e discutiram o estado atual e tendências na produção de biomassa e suas possíveis implicações para estratégias de política, comunicação e inovação para um futuro sustentável.

\section{Algumas universidades estrangeiras que visitaram USP, Unicamp e Unesp em busca de parcerias em pesquisas em bioenergia}

\begin{tabular}{l}
\hline Alexander von Humboldt Foundation \\
\hline Anglia Ruskin University \\
\hline Birmingham University \\
\hline Brunel University \\
\hline Cardiff University \\
\hline Chalmers University \\
\hline CIRED - França \\
\hline Copenhagen University \\
\hline Cranfield University \\
\hline Delft University of Technology \\
\hline Durham University \\
\hline Dublin Business School \\
\hline Dublin City University \\
\hline Durham University \\
\hline Eindhoven University \\
\hline Goldsmiths University of London \\
\hline Glasgow Caledonian University \\
\hline Goldsmiths University College Dublin \\
\hline IMC \\
\hline
\end{tabular}

\begin{tabular}{l}
\hline Imperial College \\
\hline Kazan National Research Technological University \\
\hline University of Applied Sciences \\
\hline Ingolstadt University \\
\hline Humboldt University \\
\hline Kiel University \\
\hline Loyola Marymount University - LMU \\
\hline Lund University \\
\hline Mälardalen University \\
\hline Nottingham University \\
\hline Oxford University \\
\hline Technishe Universität Munchen - TUM \\
\hline Stellenbosch University \\
\hline Swansea University \\
\hline Universidad Industrial de Santander - UIS \\
\hline Universidade de Coimbra \\
\hline University of Bath \\
\hline University of Bristol \\
\hline University College of Cork \\
\hline
\end{tabular}

\begin{tabular}{l}
\hline University of Derby \\
\hline University of Hamburg \\
\hline University of Leeds \\
\hline University of Limerick \\
\hline University of Liverpool \\
\hline University of Lódz \\
\hline University of London \\
\hline University of Manchester \\
\hline University of Münster \\
\hline University of Oulu \\
\hline Universität Potsdam \\
\hline University of Southampton \\
\hline University of Strathclyde \\
\hline University of Warwick \\
\hline Utrecht University \\
\hline Wageningen University \\
\hline Waterford Institute of Technology - TSSG \\
\hline
\end{tabular}




\section{Bioenergia da cana-de-açúcar, uma real contribuição para o Brasil e para 0 mundo}

Nascido da convicção de empresários e apoiados por cientistas e governo, o Proálcool foi indiscutivelmente o maior programa de estímulo à programação de biocombustíveis renováveis no mundo. Nesse sentido, a produção da bioenergia da cana-de-açúcar ofereceu e ainda oferece importantes contribuições à economia brasileira e ao mundo.

Como o objetivo inicial era economizar divisas substituindo gasolina importada, Plínio Nastari, da Datagro estimou que, desde 1975, tenham sido substituídos 2,41 bilhões de barris de gasolina ${ }^{16}$, uma marca muito relevante para o Brasil, um país que dispõe de reservas de petróleo e condensados estimadas entre 13,1 e 16,6 bilhões de barris, dependendo do critério considerado, incluindo reservas do pré-sal. Nastari estimou também que o valor da gasolina substituída represente economia acumulada de mais de 381 bilhões de dólares (em dólares constantes de dezembro de 2014), incluindo o custo da dívida externa evitada; e que desde 1975 o uso do etanol combustível tenha evitado emissões de mais de 800 milhões de toneladas de $\mathrm{CO}_{2}$ equivalente e, apenas em 2014, mais de 50 milhões de toneladas. Estima ainda que, em 2015, o etanol combustível, anidro e hidratado, tenha substituído $42 \%$ de toda a gasolina consumida no país.

O assunto da bioenergia sustentável da cana-de-açúcar é provavelmente o tema que mais atrai interesses internacionais sobre o Brasil, sendo referência na contribuição da ciência em colaboração com empresários e governo. No entanto, de 2008 para cá, esse cenário favorável tem sofrido substanciamente em decorrência de diversos fatores, alguns deles externos (crise na Europa) e outros internos, o que pode prejudicar o aproveitamento desse potencial para o país.

\section{Aspectos conjunturais da presente crise (2008 a 2015)}

Alguns fatos, internos e externos, aconteceram nesse período quase que simultaneamente, precipitando uma longa crise no setor sucroalcooleiro:

16 Considerando 1 barril $=159$ litros, portanto cerca de 383 bilhões de litros. 
a. Petróleo: o governo federal e a Petrobras anunciaram no fim de 2007 as reservas de petróleo do pré-sal, levando a uma priorização desse setor em detrimento das outras fontes renováveis no país. Esse fenômeno viria a ganhar intensidade maior com o início da produção de gás de xisto (shale gas) nos EUA, fazendo cair substancialmente os preços do petróleo no mercado internacional do patamar de 100 dólares para cerca de 40 dólares/barril, a partir do segundo semestre de 2014. Note-se que a faixa de viabilidade econômica de exploração do petróleo do pré-sal está entre 40 dólares e 70 dólares/barril.

b. Diminuição da ênfase internacional sobre os biocombustíveis: uma onda de más notícias divulgadas pela mídia, inclusive revistas científicas, trazem considerações e preocupações sobre o impacto da produção dos biocombustíveis: a competição com a produção de alimentos, a dúvida sobre sua capacidade de mitigar emissões de GEE, as dificuldades de produzir biocombustíveis de segunda e terceira gerações e o reconhecimento de que não há muita terra agrícola disponível no mundo, com exceção da América Latina e África, justamente regiões onde existem problemas ligados à segurança alimentar e energética.

c. Falta de políticas consistentes no planejamento energético nacional e em específico de apoio aos biocombustíveis: o país tem tido nas últimas décadas uma grande dificuldade em organizar o planejamento energético de médio e longo prazo. Em meados da década de 1990, assistimos às privatizações de empresas do setor elétrico e à criação das agências reguladoras, ANEEL e ANP. No entanto, nos útimos anos, em função de problemas conjunturais e estruturais, o país voltou a ter problemas no setor elétrico. Esses problemas fazem ressurgir as oportunidades para as fontes renováveis de energia, em particular da bioeletricidade.

No âmbito do Estado de São Paulo, o Secretário de Energia João Carlos de Souza Meirelles lançou em 26 de agosto de 2015 o programa São Paulo na Rede Elétrica, que pretende ampliar o fornecimento de energia para a rede elétrica produzida a partir da queima da palha, do bagaço da cana-de-açúcar e outros insumos, como cavaco de madeira. Um estudo feito pela pasta mapeou as usinas existentes e identificou a sua produção, consumo e exportação de energia excedente para a rede elétrica. Foram analisadas 166 instalações, que assinaram o Protocolo Agroambiental. Deste total, 34 delas ficam na região nordeste do Estado, a uma distância de $100 \mathrm{~km}$ do município de Morro Agudo. Dez foram selecionadas para um projeto-piloto em conjunto com a CPFL, concessionária de energia da região. 
"Considerando o excedente de energia que essas 10 usinas conseguem produzir na região de Morro Agudo, conseguiríamos aumentar o fornecimento para a rede em $237 \mathrm{MW}$, o que significa o consumo anual de uma cidade como Ribeirão Preto, que possuiu 600 mil habitantes", disse o secretário de Energia, João Carlos de Souza Meirelles

Fonte: <www.energia.sp.gov.br/lenoticia.php?id=764>.

No campo dos combustíveis líquidos, em particular o etanol, houve uma dificuldade de se definir uma política fiscal sustentável para o setor. Um exemplo mais recente (2008-2014) foi a suspensão da Contribuição de Intervenção do Domínio Econômico (CIDE) da gasolina, o que na prática se caracterizou como um estímulo ao consumo excessivo de gasolina importada em detrimento do etanol produzido nacionalmente.

d. Clima e baixa produtividade: as variações climáticas têm diminuído a incidência de chuvas no Sudeste brasileiro, justamente a região onde se concentra a maior parte da produção de cana no país. Este fenômeno, associado às más práticas, tem causado uma diminuição na produtividade da cana $\mathrm{e}$ consequente elevação de custos de produção.

Todos esses fatores, somados, são responsáveis pela geração de uma crise bastante grave no setor sucroalcooleiro no Brasil. Essa crise, e a respectiva falta de horizonte de médio e longo prazos, fez os investidores suspenderem a construção de novas usinas, além de fecharem outras. A produção de cana, açúcar e etanol ficou praticamente estagnada por vários anos a partir de 2008.

O pré-sal não é uma opção que exclui o etanol porque o país pode, perfeitamente, aproveitar as duas possibilidades de forma integrada. No entanto, os investimentos devem ser realizados de forma mais equilibrada, favorecendo ambos.

Quanto à questão tributária, recentemente o governo federal reintroduziu a CIDE na gasolina, o que retomou a competitividade do etanol frente à gasolina. No entanto, falta ainda um adequado equacionamento para a questão dos estoques reguladores da oferta-demanda de etanol. Uma possibilidade que tem sido aventada é a criação de um "mercado futuro" para o etanol, criado, por exemplo, na BM\&F de São Paulo, ou algum outro mecanismo, como os leilões usados no mercado de energia elétrica. 
No campo do setor elétrico, novas medidas são necessárias, como, por exemplo, um maior incentivo à produção de bioeletricidade de cana, o que pode fazer o setor contribuir de forma mais decisiva na matriz energética nacional.

\section{A grande dimensão da produção de cana, açúçar e etanol no Brasil, após 40 anos de Proálcool}

Tendo como cenário todas as influências que o setor sucroenergético do Brasil recebeu, nestes quarenta anos após a criação do Proálcool, houve uma grande expansão deste agronegócio. Em grandes números, citamos a evolução da produção de cana e de seus principais produtos:

- Cana-de-açúcar: de 68 milhões de toneladas de cana por safra (TCS) em 1975/1976, para 652 milhões TCS em 2013/2014.

- Açúcar: de 6 milhões de toneladas em 1975/1976, para 38 milhões de toneladas em 2012/2013.

- Etanol: de 550 milhões de litros em 1975/1976, para 28 bilhões de litros em 2014/2015.

A Figura 147 apresenta essa evolução (Olivério; Boscariol, 2013).

Primeiro grande salto, de 1975/1976 a 1985/1986, com a produção de cana aumentando de 68 milhões TCS para 223 milhões TCS, devido ao aumento de demanda de etanol no mercado interno (de 550 milhões para perto de 12 bilhões de litros, devido à implantação do Proálcool). Nesse período, por influência do grande aumento no processamento de cana e na produção de etanol, que gerou grande demanda por novas usinas e novos equipamentos, desenvolveu-se intensamente a tecnologia industrial desses setores da usina, setores estes que são ainda hoje a sólida base e referência para os desenvolvimentos mais recentes. Note-se que os processos e equipamentos para a produção de açúcar, por não ter a demanda um crescimento expressivo, não evoluíram nesse período, e constata-se que a tecnologia voltada à produção de açúcar permaneceu bastante defasada no Brasil comparativamente às usinas do exterior.

De 1985/1986 a 1993/1994 a produção de cana se estabilizou, ora sendo produzindo mais etanol, ora mais açúcar, com pequenas variações. 


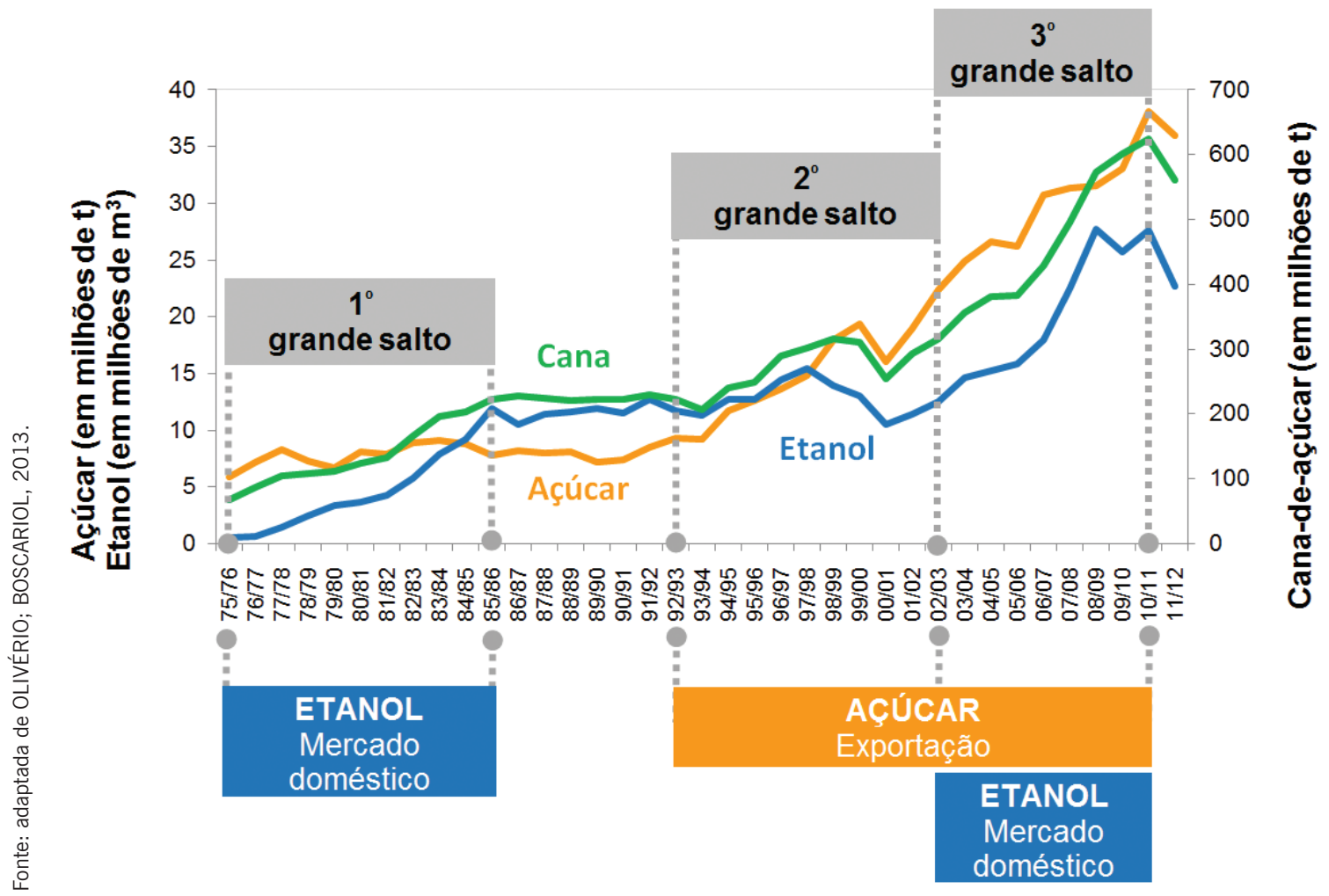

Figura 147: Evolução da produção brasileira de cana, açúcar e etanol e os motivos dessa expansão.

Segundo grande salto, com a produção de 218 milhões TCS em 1993/1994 se elevando para 320 milhões TCS em 2002/2003, devido ao aumento de produção de açúcar de 9 milhões para 23 milhões de toneladas destinadas ao mercado de exportação. Destaque-se que, até este estágio, a tecnologia de produção de açúcar se mantinha estagnada aos níveis da década de 1970. Com o crescimento da produção, criou-se o mercado que propiciou ao Brasil, em pouco tempo, igualar e até superar o estado da técnica mundial.

Em 2002/2003 se inicia o terceiro grande salto, decorrente do aumento da produção de etanol destinada ao mercado interno devido principalmente à introdução dos veículos flex (de 12 bilhões em 2002/2003 para 30,4 bilhões de litros em 2015/2016), do aumento de produção de açúcar para exportação (produção 
total de 23 milhões de toneladas em 2002/2003 para 33,9 milhões de toneladas em 2015/2016), aumento do qual resultou a necessidade de elevação da produção de cana de 320 milhões para 669,9 milhões TCS em 2015/2016. Também a partir de 2002, com o lançamento da Proinfa, criaram-se os mecanismos institucionais para a produção e comercialização da bioeletricidade excedente, produzida a partir do bagaço e, mais recentemente, também da palha de cana (Olivério; Ribeiro, 2006). Esta condição de crescimento acelerado do processamento da cana e da produção de açúcar, de etanol e da bioeletricidade cria um novo estímulo para o desenvolvimento tecnológico da usina como um todo, que é o que se observa atualmente. Destaque-se que a produção de cana, que sofre o impacto do aumento dos seus principais produtos etanol e açúcar, nesses quarenta anos de Proálcool aumentou cerca de dez vezes, de 68 milhões TCS para 669,9 milhões TCS. Esses números conferem ao país a condição de primeiro produtor mundial de cana, de açúcar e de etanol de cana.

Do aniversário de trinta anos ao aniversário de quarenta anos do Proálcool, as usinas elevaram o processamento de cana de cerca de 380 milhões de TCS para acima de 669,9 milhões de TCS, representando um aumento da ordem de $70 \%$.

Como resultado desse estímulo de mercado, o setor industrial do agronegócio de cana-de-açúcar experimentou novo ciclo de evolução tecnológica, que se traduziu em aumentos na produtividade, rendimentos e eficiências na produção de açúcar, etanol e bioeletricidade. Houve, também, influência da sustentabilidade, que motivou sensível elevação do desempenho das usinas nesse aspecto.

Apresentam-se na Tabela 11 os desempenhos das usinas quanto à tecnologia industrial disponível, no estado da arte, após quarenta anos do Proálcool (Olivério; Boscariol, 2013). Vale comparar com os melhores desempenhos nos décimo e trigésimo aniversários do programa, já apresentados. Verifica-se que houve sensível crescimento na performance do setor industrial canavieiro, mas que, de $2009 \mathrm{em}$ diante, sentiu-se o efeito da crise no setor sucroalcooleiro. 
Tabela 11: Resultados da evolução tecnológica do setor industrial, 1975-2013

\begin{tabular}{|c|c|c|c|}
\hline & Produtos Dedini & $\begin{array}{l}\text { Início do } \\
\text { Proálcool }\end{array}$ & $\begin{array}{l}\text { Estado } \\
\text { da arte }\end{array}$ \\
\hline \multicolumn{4}{|l|}{ 1. Aumento de capacidade de produção/equipamento } \\
\hline $\begin{array}{l}\text { Capacidade de moagem (TCD) - } \\
6 \times 78^{\prime \prime}\end{array}$ & Desfibrador vertical/Tandem de moendas & 5.500 & 15.000 \\
\hline Tempo de fermentação $(\mathrm{h})$ & Fermentação batelada/Contínua & 24 & $6-8$ \\
\hline Teor alcoólico do vinho $\left({ }^{\circ} \mathrm{GL}\right)$ & Ecoferm & 6,5 & até 16 \\
\hline \multicolumn{4}{|l|}{ 2. Aumento de eficiência/rendimento } \\
\hline Rendimento extração (\% aç. cana) - 6 ternos & Tandem de moendas/Difusor modular & 93 & $97 / 98$ \\
\hline Rendimento fermentativo (\%) & Ecoferm & 80 & 92 \\
\hline Rendimento da destilação (\%) & Destiltech & 98 & 99,5 \\
\hline \multicolumn{4}{|l|}{ 3. Consumo/eficiência energética } \\
\hline Consumo total de vapor (kg/t cana) & Tecnologia Dedini & 600 & 320 \\
\hline Consumo vapor-anidro (kg/L) & Split-feed + Membrana/Peneira molecular & 4,5 & 2,0 \\
\hline Caldeira-Eficiência (\% PCI) & AZ/AT/Single-drum & 66 & 89 \\
\hline Pressão (bar)/Temperatura $\left({ }^{\circ} \mathrm{C}\right)$ & AZ/AT/Single-drum & $21 / 300$ & $120 / 540$ \\
\hline Biometano a partir de vinhaça $\left(\mathrm{Nm}^{3} / /\right.$ etanol) & METHAX & - & 0,1 \\
\hline \multicolumn{4}{|l|}{ 4. Parâmetros globais } \\
\hline Rendimento total (L álc.hidr./t cana) & Tecnologia Dedini & 66 & 87 \\
\hline Bagaço excedente (\%) - usina de etanol & Tecnologia Dedini & até 8 & até 78 \\
\hline $\begin{array}{l}\text { Eletricidade excedente para a rede, usina de etanol, } 12.000 \text { TCD, } \\
\text { combustível: bagaço, unidade: MW }\end{array}$ & Tecnologia Dedini & - & 50,7 \\
\hline $\begin{array}{l}\text { Eletricidade excedente para a rede, usina de etanol, } 12.000 \mathrm{TCD} \text {, } \\
\text { combustivel: bagaço }+50 \% / 100 \% \text { palha, unidade: MW }\end{array}$ & Tecnologia Dedini & - & $84 / 112$ \\
\hline Produção de vinhaça (L vinhaça/L etanol) & Ecoferm/DCV & 13 & $5,0 / 0,8$ \\
\hline Consumo de água (L água/L etanol) & Usina de água & 187 & $(-) 3,7$ \\
\hline
\end{tabular}

Notas: TCD, tonelada de cana por dia; PCI, poder calorífico inferior, baseado no bagaço; Ecoferm, sistema de fermentação até $16^{\circ} \mathrm{GL}$; Destiltech, planta de destilação de etanol com recirculação de flegma; METHAX, planta de biodigestão de vinhaça com produçãa de biogás elou biometano; DCV, planta de concentração de vinhaça por evaporação. 
A evolução apresentada na Tabela 11 demonstra um notável desenvolvimento nos diferentes processos tecnológicos do setor industrial, gerando inúmeras histórias de sucesso. Vamos comentar somente o aumento da capacidade de moagem: 6 ternos de 78", que processavam 5.500 TCD em 1975, foram evoluindo para 10.000 TCD em 1985, 14.000 TCD em 2005 e, finalmente, 15.000 TCD em 2013.

Consideramos esta evolução, que se processou em inúmeros pequenos estágios, um importante e apropriado exemplo para ilustrar como melhorias contínuas, de pequena dimensão incremental, vieram a resultar em um expressivo aumento final de desempenho.

Esse resultado advém do trabalho diário das engenharias do produto, interagindo experimentalmente com as usinas. Vale destacar os trabalhos de especialistas como Sidney Brunelli e Mario Myaiese, e os gerentes de engenharia de empresas Pedro Eduardo Pinho de Assis e Antonio Carlos D’Ávila.

\section{A pesquisa que ainda é necessária}

Evidentemente, a história do Proálcool não termina aqui. Os desenvolvimentos no setor de bioenergia que nos trouxeram até aqui não garantem, necessariamente, uma posição confortável no futuro. Vencer os desafios que se apresentam requer investimentos em pesquisa.

É desejável que haja maior integração da pesquisa com uma abordagem multidisciplinar, estimulando sinergias e o aumento da massa crítica, do impacto e abrangência dos esforços em pesquisa e inovação. É importante atrair jovens pesquisadores em áreas de ponta e parcerias internacionais, diversificando as áreas de atuação, para que a pesquisa conduzida seja do interesse de uma comunidade ainda maior, tanto da indústria nacional quanto internacional.

Os tópicos que merecem atenção da comunidade científica incluem:

\section{Pesquisa básica para avançar o conhecimento em bioenergia}

Pesquisa em agronomia, ciclos biogeoquímicos, genômica de plantas e micro-organismos, biologia sintética e de sistemas, genética comparativa e evolutiva de plantas utilizadas como fonte de biomassa, 
fotossíntese, crescimento e desenvolvimento de plantas, adaptação ao ambiente, resposta a estresses bióticos e abióticos, resiliência a climas futuros.

Pesquisa em micro-organismos fermentadores, lignocelulolíticos e algas que permitam explorar as diferentes fontes de biomassa, compreender os fenômenos que regulam a eficiência do uso das fontes de carbono sem perdas e com economia de água. Desdobramentos de coprodutos e compostos químicos de valor agregado que possam resultar em novas aplicações, por exemplo, rotas para aumento da sustentabilidade no conceito no waste.

Pesquisa que integre ciências ao longo de todo o ciclo de produção de bioenergia (como em abordagens do tipo landscape level planning), gerando conhecimento básico sobre o uso da terra, ciclos biogeoquímicos (água, carbono, nitrogênio) e climáticos.

\section{Pesquisa aplicada ao aumento da produtividade e do tempo de operação de usinas de bioetanol, bioeletricidade e biorrefinarias}

A indústria do bioetanol produz durante cerca de 180 dias ao ano. A produtividade da cana-de-açúcar precisa ser grandemente aumentada e o tempo de operação das usinas ampliado dos 180 dias anuais atuais para possivelmente uma operação contínua. A média comercial de produção atual de cana-de-açúcar está em torno de 80 toneladas por hectare por ano. O potencial teórico é de 380 toneladas por hectare por ano. Os desafios para o aumento da produtividade no campo envolvem fatores agronômicos, edáficos, ambientais, fisiológicos e biotecnológicos. Nas usinas, os desafios incluem a produção integrada de coprodutos e energia e o uso eficiente de novas fontes de biomassa.

\section{Novas práticas agronômicas em cana-de-açúcar para aumento de produtividade e sustentabilidade}

Pesquisas que levem a saltos tecnológicos em manejo e conservação do solo, irrigação e uso eficiente de água e recursos hídricos, canteirização, agricultura de precisão, fertilização, controle de pragas e doenças, e aumento de longevidade do canavial. Uso da palha de cana não somente para a produção tradicional de bioenergia como para etanol de segunda geração. Entre os desafios já identificados estão a definição do impacto ambiental da remoção da palha, sua economicidade e as consequências agroambientais de sua manutenção sobre o solo. 


\section{Melhoramento genético da cana-de-açúcar}

Pesquisa para o desenvolvimento de novos cultivares de plantas para bioenergia usando avanços recentes da biotecnologia e genômica, que gerem plantas com tolerância à seca, tolerância a altas/baixas temperaturas para expansão de áreas cultivadas, resistência a pragas e doenças, desenvolvimento da cana-energia, expansão e caracterização de bancos de germoplasmas.

\section{Etanol celulósico, produção integrada de coprodutos e energia na usina}

Pesquisas para o desenvolvimento de novos sistemas de biorrefinarias com produção integrada de novos coprodutos ou reaproveitamento dos produtos atuais para aumento de produtividade, agregando valor ao setor e produzindo um ciclo de vida mais favorável dos processos de produção de etanol celulósico, com redução de custos e de consumo de água e energia, novas rotas ou rotas mais eficientes para a produção de produtos à base de biomassa.

\section{Bioeletricidade e biomassas fora da rota dos combustiveis liquidos}

A bioeletricidade tem tido importância econômica e energética crescente. As tecnologias de combustão têm evoluído e buscam novos desenvolvimentos. Alternativas eficientes de produção de energia incluem a utilização de turbinas movidas a gás oriundo da gaseificação do bagaço. Outra forma de aumentar a produção de energia é por meio da geração de biogás decorrente da fermentação da vinhaça e de outros resíduos da indústria ou provenientes do campo. Atualmente, nas usinas, o bagaço é a principal matéria prima para combustão, mas há interesse crescente em palha, cuja composição mineral pode afetar equipamentos, e em outras matérias-primas externas.

\section{Pesquisa aplicada para ampliar e diversificar as fontes de biomassa para bioenergia}

A ampliação do período de operação das usinas é importante para a redução dos custos. Uma alternativa é a produção de biomassas que possam ser utilizadas no período de entressafra da cana-de-açúcar ou o melhor aproveitamento de resíduos agrícolas. Processos de integração de primeira e segunda gerações 
abrem muitas opções agrícolas envolvendo culturas açucareiras e materiais celulósicos. Um desafio é a necessidade de a biomassa ser suficientemente produtiva para permitir a produção de etanol e, ao mesmo tempo, gerar a energia necessária para a operação dos processos da usina.

Fontes de biomassa de interesse incluem - mas não se restringem a - sorgo, palha de cana-de-açúcar e outros resíduos agrícolas.

O sorgo se encontra no portfólio de plantas para a produção de bioenergia por ser relativamente tolerante à seca, ser fonte de amido, sacarose e de celulose, e poder ser cultivado na entressafra da cana-de-açúcar. Essa cultura já é utilizada para a produção de etanol em diversos países.

A expansão das fronteiras agrícolas, o uso potencial de solos degradados e terras marginais, assim como a resiliência às mudanças climáticas, representam desafios para a produção vegetal, tanto para a bioenergia quanto para outros fins.

O Brasil conta com 6 milhões de hectares de eucalipto e pínus plantados, e apresenta a maior produtividade de madeira do mundo. É uma biomassa já estabelecida que contribui em $11 \%$ para a matriz energética brasileira. Tem ainda grande potencial de aproveitamento adicional via produção de etanol celulósico e como matéria-prima para a indústria química. A biomassa florestal tem plantio factível em áreas marginais e de alta declividade, áreas não ocupadas atualmente pela cana-de-açúcar e outras culturas energéticas, contribuindo com o fornecimento de biomassa para bioenergia e melhor aproveitamento da terra.

\section{Pesquisa aplicada à logística da produção de biomassa}

Biomassas são produtos volumosos e de baixo valor agregado e, geralmente, estão entre os maiores fatores de custo para a produção de bioenergia. Por exemplo, as operações de corte, carregamento e transporte representam de $20 \%$ a $40 \%$ do custo de produção de cana-de-açúcar nas usinas. Parte dos aspectos de logística demanda soluções de engenharia e a criação de equipamentos multiuso e eficientes. A logística de produção e distribuição de biocombustíveis também é um foco de pesquisa necessário. 


\section{Pesquisa aplicada à produção de biocombustivel para aviação e veículos pesados}

A indústria aeronáutica internacional tem metas para utilizar combustíveis renováveis e reduzir as emissões de $\mathrm{CO}_{2}$. Para aviões não há opções no horizonte além de biocombustíveis líquidos. Esses devem ser do tipo drop-in, ou seja, que não necessitam de alterações nos motores ou turbinas. Em virtude do destacado potencial para produção de biomassa e do já importante e crescente mercado aeronáutico, o Brasil tem grande oportunidade de se destacar na área de biocombustíveis para aviação e também de aplicações para veículos pesados e embarcações.

\section{Pesquisa do impacto ambiental, social e econômico da expansão da produção de cana- -de-açúcar e outras fontes de biomassa para bioenergia}

O Brasil se destaca mundialmente como grande produtor de biomassa e também por sua matriz energética em grande parte renovável. A disponibilidade de terras e clima adequado fazem com que o Brasil possa contribuir significativamente para a substituição de derivados de petróleo em escala mundial. É essencial, no entanto, entender qual é o impacto ambiental, social e econômico da expansão da produção de biomassa e bioenergia no país. Aqui se destaca a necessidade de estudos integrados de toda a cadeia produtiva.

\section{Desenvolvimentos futuros e conclusões}

Hoje, o Brasil é o líder das pesquisas em cana-de-açúcar. Esta liderança foi conquistada durante os últimos quarenta anos, ficando mais evidente depois de 2000 e sendo muito influenciada pelos esforços desenvolvidos pela Fapesp, universidades e centros de pesquisa. Vale ressaltar que, sobretudo antes de 2000, ocorreram resultados importantes de pesquisas do Planalsucar (depois Ridesa), CTC e IAC, com o lançamento de inúmeras variedades comerciais de cana, melhorias na extração do caldo, fermentação, manejo agrícola, mecanização e logística na colheita e transporte da cana.

A bioenergia moderna desempenha hoje um papel importante na economia brasileira. Isso pode ser observado nos setores: madeira para produção de celulose, papel, cimento, aço e cana-de-açúcar na indústria do etanol e bioeletricidade. 
A Conferência do Clima - COP 21, realizada em dezembro de 2015, em Paris, França, foi uma ocasião à qual os países levaram suas propostas e políticas visando contribuir para a redução das emissões dos gases do efeito estufa e para a correspondente atenuação da crise climática que vivemos hoje no mundo. A proposta encaminhada pelo governo brasileiro representa um avanço e está fundamentada principalmente em dois eixos: a redução do desmatamento e a ampliação do uso de fontes renováveis na matriz energética. Nesse sentido, a expansão da produção sustentável de etanol e bioeletricidade, sobretudo utilizando pastagens degradadas, podem, de forma direta, substituir a gasolina e evitar o uso de fontes fósseis não renováveis, e, de forma indireta, promover a redução do desmatamento, uma espécie de "ILUC negativo". Portanto, o cenário que se descortina para o etanol e outros produtos da cana-de-açúcar no Brasil é extremamente auspicioso. Há, no entanto, que se construir esse futuro sustentável por meio de políticas públicas e compromissos envolvendo nossa sociedade em fóruns nacionais e internacionais.

Ao Brasil é reservado um futuro próspero no campo da bioenergia. A participação da cana-de-açúcar na matriz energética brasileira tem crescido 1\% ao ano desde 2002, já atingindo 19\% em 2010. Em outros campos, a biotecnologia (alimentos, saúde, química verde e materiais) tem desempenhado um importante papel na economia brasileira e também podem se converter em um importante condutor do desenvolvimento sustentável no Brasil e sua inserção na economia mundial.

No entanto, a partir 2008-2009 houve uma interrupção no crescimento e na entrada em operação de novos projetos para produção de etanol de cana-de-açúcar, embora o mercado interno para o etanol e bioeletricidade de cana-de-açúcar tenda a crescer nos próximos anos. Existe também um mercado promissor para outros biocombustíveis, como os biocombustíveis para a aviação no Brasil.

Os investimentos de pesquisa e a formação de recursos humanos na área de bioenergia devem igualmente crescer proporcionalmente. Espera-se, sobretudo com os novos centros de pesquisa, que a pós-graduação também ajude a formar quadros competentes e em todos os níveis para fazer frente aos desafios existentes.

Quanto à tecnologia industrial, também cabem as perguntas: 1) como serão as futuras usinas; 2) que tecnologias serão utilizadas; 3) quais serão as capacidades de processamento; 4) quais produtos serão 
oferecidos pelas novas usinas? Apenas os tradicionais - açúcar, etanol e bioeletricidade -, ou teremos novos produtos; 5) que lições aprendemos do surpreendente crescimento do setor sucroenergético, principalmente da expansão mais recente?

Esses temas citados acima, foram objeto de um trabalho de Olivério e Boscariol (2013). Para responder a essas perguntas, os autores analisaram o perfil de evolução dos projetos das recentes 117 "usinas greenfield" instaladas no Brasil a partir de 2003, com o objetivo de levantar as tendências de evolução das futuras usinas quanto a produtos, capacidades e tecnologias. A conclusão é que os novos greenfields serão concebidos e projetados atendendo a cinco vetores direcionadores dessas tendências:

- aumento da capacidade e da produtividade dos equipamentos e das usinas;

- aumento das eficiências e dos rendimentos;

- aumento da sustentabilidade;

- sinergia e integração com outros processos e/ou produtos;

- desenvolvimento de produtos de maior valor agregado da cana-de-açúcar e da usina canavieira.

Essa tendência de evolução é um desafio que a indústria de equipamentos do Brasil se considera em condições de atender, tanto na capacitação quanto na competitividade.

O caso do sucesso brasileiro no uso de etanol de cana-de-açúcar pode ser, assim, entendido como uma trajetória de aprendizado, baseado, na maior parte das vezes, em inovações incrementais. Tiveram papel central os centros de pesquisa, ligados ao setor agrícola, e seus respectivos programas de variedades, e, mais recentemente, as empresas que se formaram, consideradas "filhas" dos centros mais tradicionais.

O Proálcool acaba de completar 40 anos e outra fase já teve início nos últimos anos, tendo a sustentabilidade como eixo e devendo impactar a forma como fazemos agricultura, os processos de transformação e redefinindo as relações socioeconômicas.

Boas notícias para o Brasil, que pode, a partir da bioenergia sustentável, construir a sociedade do futuro com base no uso moderno de biomassa! 